\title{
Evaluation of Fish Losses through Screen Gaps at Modified and Unmodified Intakes of Bonneville Dam Second Powerhouse in 2003
}

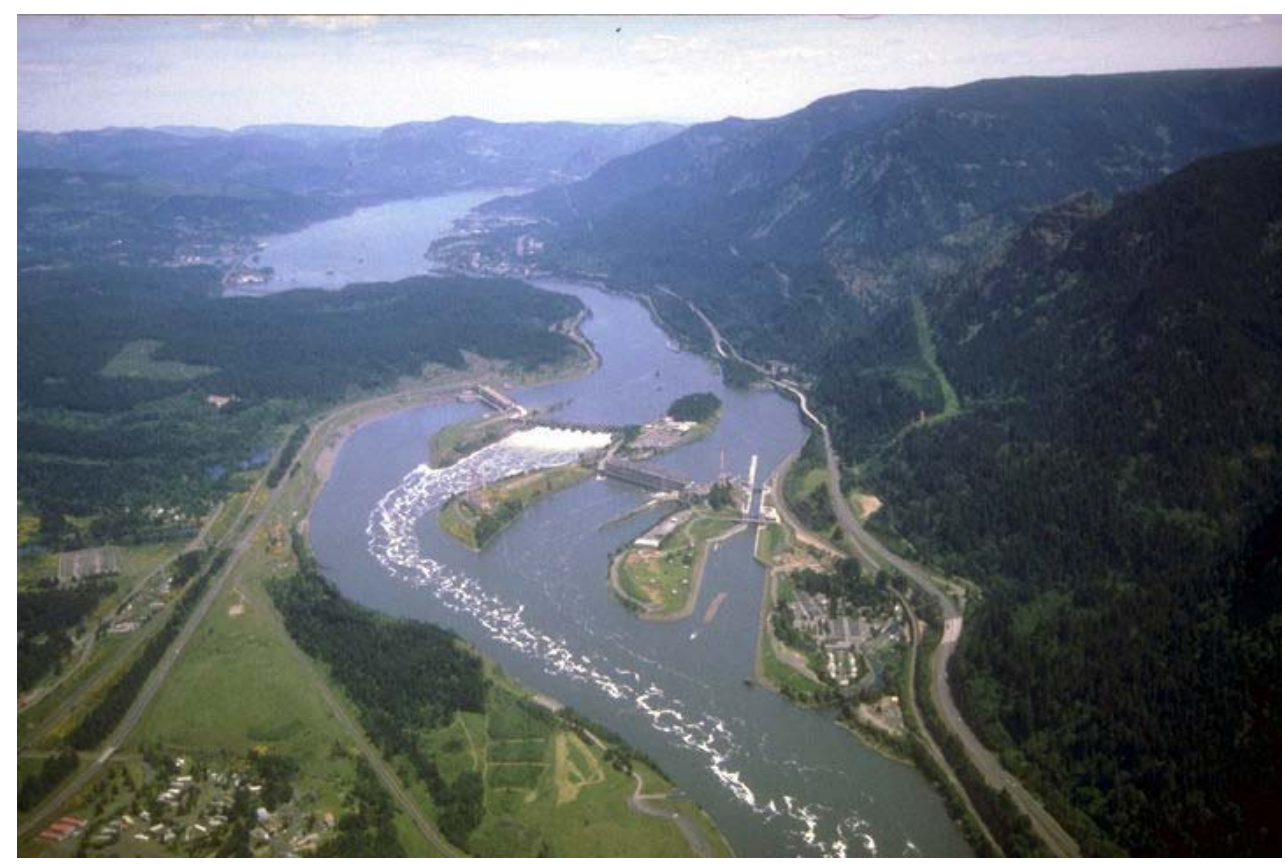

G.R. Ploskey

M.A. Weiland

C. R. Schilt

FINAL REPORT

May 2004

Prepared for the U.S. Army Corps of Engineers

Portland District, Portland, Oregon

Under a Related Services Agreement

With the U.S. Department of Energy

Contract DE-AC06-76RLO1830

\section{Pacific Northwest National Laboratory}

Operated by Battelle for the

U.S. Department of Energy 


\title{
DISCLAIMER
}

This report was prepared as an account of work sponsored by an agency of the United States Government. Neither the United States Government nor any agency thereof, nor Battelle Memorial Institute, nor any of their employees, makes any warranty, express or implied, or assumes any legal liability or responsibility for the accuracy, completeness, or usefulness of any information, apparatus, product, or process disclosed, or represents that its use would not infringe privately owned rights. Reference herein to any specific commercial product, process, or service by trade name, trademark, manufacturer, or otherwise does not necessarily constitute or imply its endorsement, recommendation, or favoring by the United States Government or any agency thereof, or Battelle Memorial Institute. The views and opinions of authors expressed herein do not necessarily state or reflect those of the United States Government or any agency thereof.

\author{
PACIFIC NORTHWEST NATIONAL LABORATORY \\ operated by \\ BATTELLE \\ for the \\ UNITED STATES DEPARTMENT OF ENERGY \\ under Contract DE-AC06-76RL01830
}

Printed in the United States of America
Available to DOE and DOE contractors from the Office of Scientific and Technical Information,
P.O. Box 62, Oak Ridge, TN 37831-0062;
ph: (865) 576-8401
fax: $(865) 576-5728$
email: reports@adonis.osti.gov

\footnotetext{
Available to the public from the National Technical Information Service, U.S. Department of Commerce, 5285 Port Royal Rd., Springfield, VA 22161 ph: (800) 553-6847 fax: $(703) 605-6900$ email: orders@ntis.fedworld.gov online ordering: http://www.ntis.gov/ordering.htm
}

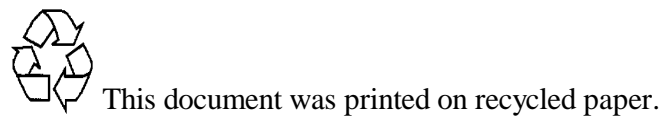




\title{
Evaluation of Fish Losses through Screen Gaps at Modified and Unmodified Intakes of Bonneville Dam Second Powerhouse in 2003
}

\author{
G.R. Ploskey \\ M.A. Weiland \\ C.R. Schilt ${ }^{(a)}$
}

FINAL REPORT

May 2004

Prepared for U.S. Army Corps of Engineers -

Portland District, Portland, Oregon

Under a Related Services Agreement

With the U.S. Department of Energy

under Contract DE-AC06 76RLO1830

CENWP MIPR No. W66QKZ20303607

Pacific Northwest National Laboratory

P.O. Box 999

Richland, Washington 99352

(a) BAE Systems, Inc., North Bonneville, Washington 
Evaluation of Fish Losses through Screen Gaps at Bonneville Second Powerhouse in 2003 


\section{Abstract}

In a 2003 study by Pacific Northwest National Laboratory (PNNL) for the U.S. Army Corps of Energy, we sampled nine gatewell slots at Bonneville Dam Second Powerhouse (B2) with a Dualfrequency Identification SONar (DIDSON) acoustic imaging device to estimate the gap loss of juvenile salmonids. Gap loss is the number of fish guided by screens but lost to turbine passage through the gaps between the tops of submerged traveling screens (STSs) and the intake ceilings. Six of the intakes (Units 15 and 17) had been modified to improve fish guidance efficiency (FGE, the proportion of fish passing above intake screens) while the three unmodified intakes at Unit 13 served as controls. All three units had similar configurations of turbine intake extensions (TIES). Intake modifications included removal of concrete between the gatewell and bulkhead slots to increase the area of the vertical barrier screen and installation of a turning vane and gap-closure device to direct more flow up into the gatewell slot.

This study was to determine if those modifications, which did increase FGE, had the added benefit of reducing gap loss. In the unmodified intakes of Unit 13 we also sampled with infrared optical cameras to evaluate the proportions of fish and non-fish objects passing through the STS gaps and found that fish composed just $28.6 \%$ of all objects in spring and $12.9 \%$ in summer. Experiments in a laboratory tank confirmed that the DIDSON detects echoes from the surfaces of waterlogged sticks, macrophytes, and other debris as well as from fish. We developed filters based on target size, motion, range at first appearance, and the number of frames in which a target was seen to discriminate between fish and nonfish images. Filtered data produced estimates within $6 \%$ of those obtained by multiplying unfiltered DIDSON counts by the fish fraction estimated from optical-camera data.

Results suggest that the intake modifications at Units 15 and 17 reduced gap loss relative to rates at unmodified Unit 13 by about $67 \%$ in spring and summer. An analysis of variance of differences in gap loss among units with modified and unmodified intakes $(n=9)$ indicated significantly higher gap loss in unmodified units than in modified units. In spring, the least-square mean rate for unmodified Unit 13 was $11.4 \%$ and this rate was significantly higher $(\mathrm{P}=0.0001)$ than rates of $3.8 \%$ at modified Unit 15 and $3.6 \%$ at modified Unit 17, which did not differ significantly. In summer, the least-square mean rate for unmodified Unit 13 was $12.6 \%$ and this rate was significantly higher $(\mathrm{P}=0.0188)$ than rates of $5.8 \%$ at modified Unit 15 and $3.4 \%$ at modified Unit 17.

In spring, unmodified Intakes 13B and 13C had higher gap losses than all other intakes, and unmodified Intake 13A gap loss also was higher than were those of all modified intakes, except perhaps that of $15 \mathrm{~A}$, which lacked a gap-closure device. In summer, unmodified Intakes 13B and 13C also had higher gap losses than all other intakes, which did not appear to differ significantly from each other, except perhaps from the loss at Intake 17C, which was consistently low. This assessment of among intake differences was based upon visual inspection of means and $95 \%$ confidence intervals because three nights of sampling per intake did not provide adequate statistical power for a formal test. The effect of intake modifications apparently was stronger than other potential effects such as intake location in the A, B, or C slot or the presence or absence of turbine intake extensions. 
Images from small sub-yearling summer migrants were much more difficult to separate from those of entrained air bubbles than were images of larger spring migrants. We recommend limiting DIDSON sampling to estimate gap loss to spring when larger juvenile salmonids are present and future studies to determine the relative contribution of the turning vane and gap-closure devices to the gap-loss reductions and FGE. 


\section{Summary}

This report describes a study of the effectiveness of intake modifications at Bonneville Dam Second Powerhouse on reducing juvenile salmonid losses through screen gaps. The study was conducted during the spring and summer of 2003 by the Pacific Northwest National Laboratory (PNNL), Richland, Washington, and BAE Systems, Inc., a subcontractor to the U.S. Army Engineer Research and Development Center (ERDC), Vicksburg, Mississippi. The U.S. Army Corps of Engineers-Portland District provided funding and oversight.

In 2001, as part of the effort to improve fish guidance efficiency (FGE, the proportion of all fish passing a turbine unit that are guided upward by screens), the U.S. Army Corps of Engineers - Portland District made modifications to the three turbine intakes at Unit 15 of Bonneville Dam's Second Powerhouse (B2). Modifications included the excavation of part of a concrete beam from the ceiling of each intake, the downward extension of the vertical barrier screens (VBSs), the installation of turning vanes to direct a higher proportion of the flow up into the gatewell slots, and the addition of gap closure devices to restrict flow through the gaps between the STSs and the intake ceilings (hereafter referred to as "the gap" or "gaps." Gaps were approximately $1.5 \mathrm{ft}$ high by the $20 \mathrm{ft}$ wide in unmodified units and about $0.5 \mathrm{ft}$ high by $20 \mathrm{ft}$ wide in modified units. All modifications were applied to Intakes 15B, 15C, 17A, $17 \mathrm{~B}$, and $17 \mathrm{C}$. Intake $15 \mathrm{~A}$ was partially modified by concrete removal, VBS extension, and the addition of a turning vane, but it did not receive a gap-closure device.

Some portion of the fish guided upward by the STS pass through a gap between the top of the STS and the intake ceiling, proceed into the turbine, and are lost from the bypass channel route, which presumably is safer for fish. This gap-loss proportion (number of fish lost through the gap divided by the number of fish passing above the screens) had been thought to be acceptably low. However, sampling with a Dual-Frequency Identification Sonar (DIDSON) device in 2002 suggested that gap losses might be much higher than determined in previous netting studies by the National Marine Fisheries Service.

This study used a DIDSON to examine the effect of gatewell modifications on the gap-loss proportion in two modified turbine units (Units 15 and 17) as compared to that in an unmodified unit (Unit 13) at B2. Unit 13 was chosen as the unmodified control unit because total passage and FGE tend to be similar among the central units (as opposed to the end units) at B2 and because turbine intake extensions (TIEs) were installed on every second intake across the powerhouse; therefore, odd-numbered units had similar arrangements of TIEs with TIES present in front of A and C intakes and absent in front of B intakes.

Model studies suggest that the combined modifications reduced the proportion of flow through the gap from $44 \%$ to $16 \%$ and increased the proportion of flow moving up the gatewell from $56 \%$ to $84 \%$.

This study investigated the passage fates of fish in modified and unmodified intakes. Objectives were as follows:

1. Deploy a down-looking DIDSON acoustic imaging device in six modified gatewells (three each at Units 15 and 17) and the three unmodified gatewells of Unit 13 and collect data on proportions of juvenile salmonids moving up into the gatewell and through the gap between the top of the screen and the ceiling of the intakes for three 8-h nighttime periods per intake each season. 
2. Test for differences in proportions of gap loss among modified versus unmodified condition, intake position (A, B, or C slots), and presence or absence of a Turbine Intake Extension.

3. Examine samples collected over a 24-h period at one intake each season to see if there were significant diel trends.

4. Examine samples collected at each of five lateral locations within gatewells to determine the distribution of gap loss within intakes.

5. In spring and summer, sample all intakes of Unit 13 with four underwater infrared optical cameras with infrared lights to confirm the presence of fish passing through the gap and the proportion of detected objects that likely were fish.

We used a DIDSON to record images of juvenile salmonids and other objects either moving up into the gatewells or passing through the gaps. The DIDSON deployment sampled both paths simultaneously and we sampled for 8-h each on three successive nights in every intake of Units 13, 15, and 17 (i.e., 9 intakes $\mathrm{x} 3$ nights $=27$ nights each season). During nighttime sampling, the DIDSON was moved among five lateral positions at 30-minute intervals. Data from optical (infrared) video sampling at unmodified Unit 13 were used to estimate the proportion of all objects passing there that could have been fish. We classified objects that we saw in the videotaped data as either "possible fish" (including definite fish and objects with shape or other appearance that was fish-like) or "non-fish" (including waterlogged sticks, pieces of macrophytes, and unidentified debris). Of all objects detected in the video data, the percentage classified as possible fish [possible fish / (possible fish + non-fish)] was only 33.6\% in spring and 13.2\% in summer. These results led us to evaluate what the DIDSON was capable of imaging and provided fractions that we could use as constant multipliers to adjust DIDSON counts of all objects in the gap to obtain an estimate of fish losses.

Since the DIDSON imaged non-fish objects as well as fish, initial counts included substantial error from misidentification of non-fish objects as fish; thus, preliminary estimates of gap loss were too high. Gatewell-bound fish were in the field of view longer than were gap-bound fish and so offered more clues for proper identification. We developed filtering criteria to separate fish from non-fish and deleted all targets that met any of following three criteria:

(1) gatewell-bound objects that were first detected at ranges of less than three meters from the DIDSON or in fewer than three frames;

(2) gap-bound objects that were not undulating or crossing stream lines and were detected in fewer than five frames in $\underline{\mathrm{A}}$ or $\underline{B}$ intakes or in fewer than six frames in $\underline{\mathrm{C}}$ intakes;

(3) maximum target image length less than $70 \mathrm{~mm}$ or more than $305 \mathrm{~mm}$ in spring or less than 70 $\mathrm{mm}$ or more than $150 \mathrm{~mm}$ in summer.

Throughout this report, we refer to the post-processing reduction of counts by applying these three criteria to specific targets as filtering, which is different from adjusting the total estimates by the application of the constant multiplier derived from the video data analysis. We were reassured when filtered and adjusted estimates were within $6 \%$ of each other.

Because of concern about debris loading of fine-mesh VBSs, a test was conducted in spring to compare gap loss at the low and high extremes of the modified turbines' one percent efficiency range. Unfortunately that turbine loading range was not reflected in measured turbine discharge on most of the days that we sampled Units 15 and 17. The within-day range in daily turbine discharges was quite variable, often exceeding the range in mean daily discharge for the unit over the course of the study. 
Because the differences in turbine discharge varied so little between "high" and "low" discharge days, we could not determine any differences in gap loss between the two conditions.

An analysis of variance of differences in gap loss among units with modified and unmodified intakes $(\mathrm{n}=9)$ indicated significantly higher gap loss in unmodified units than in modified units. In spring, the least-square mean rate of gap loss for unmodified Unit 13 was $11.4 \%$, and this rate was significantly higher $(\mathrm{P}=0.0001)$ than rates of $3.8 \%$ at modified Unit 15 and $3.6 \%$ at modified Unit 17 , which did not differ significantly. In summer, the least-square mean rate for unmodified Unit 13 was $12.6 \%$, and this rate was significantly higher $(\mathrm{P}=0.0188)$ than $5.8 \%$ at modified Unit 15 and $3.4 \%$ at modified Unit 17.

We based the assessment of among-intake differences upon visual inspection of means and $95 \%$ confidence intervals because three nights of sampling per intake did not provide adequate statistical power for a formal test. It was not feasible to sample each intake of three units for more than three nights per season with a single DIDSON. In spring, unmodified Intakes 13B and 13C had higher gap losses than all other intakes, and unmodified Intake 13A gap loss also was higher than were those of all modified intakes, except maybe that of $15 \mathrm{~A}$, which lacked a gap-closure device. In summer, unmodified Intakes 13B and 13C also had higher gap losses than all other intakes, which did not appear to differ significantly from each other, except perhaps for Intake 17C, which consistently had the lowest losses. The effect of intake modifications apparently was stronger than other potential effects such as intake location in the A, $\mathrm{B}$, or $\mathrm{C}$ slot or the presence or absence of turbine intake extensions.

Although the true magnitude of STS gap loss is unknown, both DIDSON and netting estimates indicate that gatewell modifications reduce the gap-loss proportion by about $67 \%$. DIDSON results indicated that intake modifications reduced gap loss relative to that at unmodified intakes by about $67 \%$ in spring and summer, and this effect was stronger than other potential effects such as intake location in the $\mathrm{A}, \mathrm{B}$, or $\mathrm{C}$ slot or the presence or absence of turbine intake extensions. The true magnitude of gap loss is of less importance for evaluating effects of gatewell modification on gap loss than it is for assessing effects on hydroacoustic and netting estimates of FGE. The peak in gatewell and gap passage around sunset (2000-2200 hours) in spring was consistent with the general trend in turbine passage at Bonneville Dam based upon previous studies. The horizontal distribution of fish passage into the gatewell and gap was not uniform within or among units, which indicates that moving the DIDSON laterally is important to minimize bias. The length-frequency distributions of fish detected in the gatewells and STS gaps were reasonable in spring but not in summer when compared to Smolt Monitoring Facility data (http://www.cqs.washington.edu/DART/). Differences in distributions of gatewell and gap-lost fish in summer likely resulted from inadequate detectability of sub-yearling fish oriented toward the acoustic camera while ascending the gatewell and a poor signal-to-noise ratio.

Since we had trouble discriminating between small summer migrants and bubbles in the gatewells, we recommend limiting DIDSON evaluations of gap loss to spring when mostly larger smolts pass the dam. We also recommend studies to determine the relative contribution of the turning vane and gap-closure devices to gap-loss reductions. Complete modifications to turbine intakes to improve FGE are expensive, but some benefit in terms of increased FGE and reduced gap loss may be realized by less expensive partial modifications. 
Evaluation of Fish Losses through Screen Gaps at Bonneville Second Powerhouse in 2003 


\section{Acknowledgments}

Many people made valuable contributions to this study and deserve acknowledgment. Jina Kim and Deborah Patterson with BAE SYSTEMS, INC provided substantial contributions. Jina spent many nights acquiring optical and DIDSON data, and Deborah managed and archived all of the data and processed most of the DIDSON data. The lead Corps of Engineers biologist for this project, Dennis Schwartz, provided contract oversight and coordination between the Portland District and the Bonneville Project. Tim Darland, a Biologist with the Bonneville Project, provided valuable coordination related to Project support and scheduling and provided dam operations data for this study. This study would not have been possible without the support of Randy Price and the other Project Riggers, who helped install and remove hydroacoustic equipment. Andy Debriae was the Structural Foreman and a key contact during installations. Gene LaDouceur was the Chief of Maintenance.

Dr. Larry Lawrence with the Engineering Research and Development Center oversaw the BAE Systems, Inc. contract and was supervisor of the Fisheries Engineering Team in North Bonneville, WA.

Gary Johnson of Battelle's Pacific Northwest National Laboratory reviewed the manuscript. His many helpful comments helped to make this a much better report.

John Ferguson with the National Oceanic and Atmospheric Administration (NOAA) Fisheries graciously provided us with their 2002 netting estimates of guided and unguided fish passage for Unit 17, so that we could compare them with hydroacoustic estimates from this study. 
Evaluation of Fish Losses through Screen Gaps at Bonneville Second Powerhouse in 2003 


\section{Acronyms and Abbreviations}

\begin{tabular}{ll} 
AFEP & Anadromous Fish Evaluation Program \\
ANOVA & analysis of variance \\
APL & University of Washington Applied Physics Laboratory \\
B2 & Bonneville Dam Powerhouse 2 \\
Cfs & cubic feet per second \\
COE & U.S. Army Corps of Engineers \\
DIDSON & Dual-Frequency Identification Sonar \\
EBA & effective beam angle \\
ERDC & U.S. Army Engineer Research and Development Center \\
ESBS & extended submerged bar screen \\
FGE & fish guidance efficiency at a turbine or intake [Guided / (Guided + Unguided) \\
ft & feet \\
h & hour \\
JBS & Juvenile Bypass System \\
M & meter \\
NOAA & National Oceanic and Atmospheric Administration \\
OPE & orifice passage efficiency at orifices leading from gatewell to JBS \\
PNNL & Pacific Northwest National Laboratory \\
s & second \\
SAS & Statistical Analysis System \\
STS & submerged traveling screen \\
TIE & vertical barrier screen \\
VBS & turbine intake extension \\
\hline
\end{tabular}


Evaluation of Fish Losses through Screen Gaps at Bonneville Second Powerhouse in 2003 


\subsection{Introduction}

This report describes a study of the effectiveness of intake modifications at Bonneville Dam Second Powerhouse on reducing juvenile salmonid losses through screen gaps. The study was conducted during the spring and summer of 2003 by the Pacific Northwest National Laboratory (PNNL), Richland, Washington, and BAE Systems, Inc., a subcontractor to the U.S. Army Engineer Research and Development Center (ERDC), Vicksburg, Mississippi). The U.S. Army Corps of Engineers-Portland District provided funding and oversight.

\subsection{Background}

The Bonneville Dam Second Powerhouse (B2) was completed in 1982 and the National Oceanic and Atmospheric Administration National Marine Fisheries Service (NMFS, which is now referred to as NOAA Fisheries) began evaluating its fish guidance efficiency (FGE, the proportion of all fish passing a turbine intake or unit that pass above the screen) in 1983. Initial measurements of FGE conducted in 1983 with standard-length submerged traveling screens (STSs) were less than $25 \%$ for yearling chinook salmon (Oncorhynchus tshawytscha) and coho salmon (0. kisutch) and approximately 33\% for steelhead (O. mykiss) (Gessel et al. 1991). These guidance levels were considerably lower than the expected design level of $70 \%$ or greater for all species based on the relative positions of the STSs and the presumed depth distributions of migrating juvenile fish (Krcma et al. 1984).

\subsubsection{Netting Estimates of B2 FGE and Gap Loss 1984-1994}

From 1984 to 1989, the U.S. Army Corps of Engineers (COE) and NMFS tested design modifications to improve FGE at B2. The results of this research indicated that modifications to increase flows above the STSs and smooth flows into and within the turbine intakes could substantially increase FGE for yearling chinook salmon during the spring migration (Gessel et al. 1991). While improving FGE was the primary concern of the efforts in the 1980s it was understood that some portion of the guided fish, rather than going up the gatewell to the bypass entrance orifices, could pass through the 18-inch gap between the upper end of the STS and the ceiling of the turbine intake and travel down into the turbine (see Figure 1.1). Extensive netting efforts conducted at B2 (reviewed by Gessel et al. 1991) included netting of that gap to determine the amount of "gap loss." Tests in 1985 showed that lowering the STS $0.8 \mathrm{~m}$ in conjunction with streamlining the upper trash racks to smooth and direct flow upward increased FGE to about $40 \%$ while the gap-net catch remained at less than $1 \%$. Lowering the STS $1.2 \mathrm{~m}$ increased the gapnet catch to $12 \%$, which reduced effective FGE to $29 \%$ (Gessel et al. 1986). In four 5-day test series conducted from 1987 to 1989 with the STS lowered $0.8 \mathrm{~m}$, streamlined trash racks, and turbine intake extensions (TIEs) installed in Units 11, 12, and 13, FGE ranged from 51\% to 74\%. Based on these results, STSs were lowered $0.8 \mathrm{~m}$, streamlined trash racks were installed across the powerhouse, and TIEs were set in front of every other intake in 1991.

\subsubsection{Hydroacoustic Estimates of B2 FGE - 1996-2000}

In 1993 and 1994, NMFS again estimated FGE at B2 by netting, and it averaged 57\% for yearling chinook salmon in Unit 15 with all eight units in operation. With Units 11, 12, 13, 16, 17, and 18 operating, FGE averaged 53\% in Unit 12 and 32\% in Unit 17. During all of these tests, the average gapnet catch for all species combined was less than $1 \%$ (Monk et al. 1994, 1995). 


\section{Un-modified Gatewell}

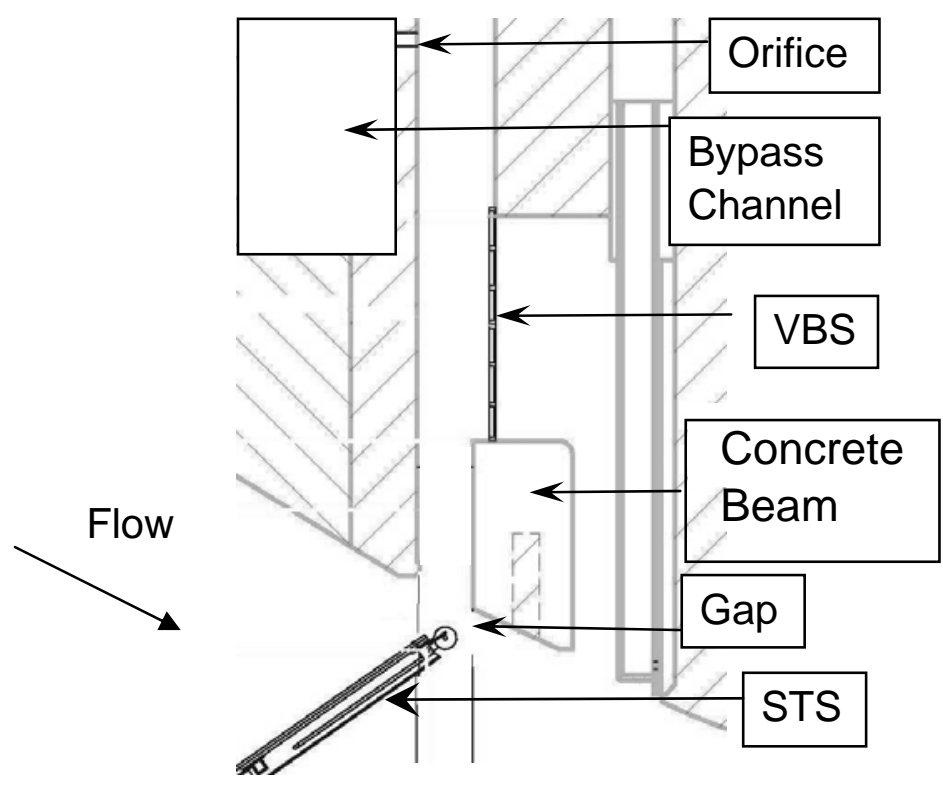

Figure 1.1. Cross section through unmodified gatewell slot of B2 intake. Abbreviations are as follows: VBS = vertical barrier screen; STS = submerged traveling screen. Modified features include the VBS, concrete beam, turning vane, and gap-closure device.

Hydroacoustic FGE estimates for all juvenile salmonids in 1996, 1998, and 2000 were similar to estimates reported in the NMFS studies described above, and FGE was lower for end units than for those nearer to the center of the powerhouse. In spring 1996, the three highest FGE estimates were $65 \%$ (Unit 12), 52\% (Unit 15), and 40\% (Unit 13), but the average for all eight units was only 37\% (Ploskey et al. 1998). In summer 1996, the average B2 FGE was only $26 \%$, and estimates ranged from $10 \%$ at Unit 11 to $42 \%$ at Unit 12). There was no significant effect of sluice-chute operation on FGE at B2 in spring or summer of 1996 (Ploskey et al. 1998). In 1998, hydroacoustic estimates of FGE for Units 11 through 13 averaged about 55\% in spring and 30\% in summer during closed sluice-chute treatments (Ploskey et al. 2001). In 2000, the fish-passage efficiency of B2 based upon sampling of all units was $54 \%$ in spring and 35\% in summer (Ploskey et al. 2002). Gap loss was not addressed in these studies.

\subsubsection{Hydraulic Model Studies of B2 Flow and Gap Loss Potential at ERDC}

Hydraulic model studies carried out at a 25:1 scale physical model of the unmodified B2 intakes at the Hydraulics Laboratory of the Engineer Research and Development Center, Vicksburg, Mississippi, predicted flows of $270 \mathrm{cfs}$ into the gatewell slot and $215 \mathrm{cfs}$ over the top of the STSs (i.e., about $44 \%$ of the total flow was going through the gap) in unmodified gatewells. These results suggested the potential for gap loss might be substantially higher than that indicated by netting data, and that there was potential for increasing gatewell flow and FGE. Design engineers produced the following modifications to further improve FGE and control gap loss at B2 turbine intakes:

(1) The height of the vertical barrier screen (VBS) would be extended downward by the partial removal of the concrete beam extending across the $20-\mathrm{ft}$ width of the gatewell. 
(2) Flow up the gatewell slot would be increased by the installation of a $20-\mathrm{ft}$ wide, 4 -ft high turning vane near the top of the STS.

(3) A gap-closure device would be installed on the intake ceiling downstream from the top edge of the STS.

(4) Screen mesh openings on the new VBS were decreased to 0.08 inches, producing a porosity of $44 \%$ to meet new design criteria for salmonid fry established by the NOAA Fisheries (National Marine Fisheries Service 2000).

These combined modifications were tested in a 25:1 scale hydraulic model; gatewell flows of 480 $\mathrm{ft}^{3} / \mathrm{s}$ and gap flows of $90 \mathrm{ft}^{3} / \mathrm{s}$ were produced. Therefore, the combined modifications reduced the proportion of flow through the model intake's gap from about $44 \%$ in the unmodified condition to about $16 \%$ in the modified model. The modifications increased the proportion of flow moving up the model's gatewell from about $56 \%$ to about $84 \%$. The increase in flow proportion up the gatewells vs. through the gaps that were predicted by the hydraulic model are summarized in Table 1.1.

Table 1.1. Gap dimensions and Proportions of total turbine intake flow based on results from a 1:25 scale hydraulic model at the Engineering Research and Development Center, Vicksburg, MS

\begin{tabular}{|l|c|c|}
\hline \multicolumn{1}{|c|}{ Metric } & Unmodified & Modified \\
\hline Gap Dimensions at Full Operating Scale & 18 in X 20 ft. & 6 in X 20 ft \\
\hline Proportion of Total Intake Flow through Gap & $44 \%$ & $16 \%$ \\
\hline Proportion of Total Intake Flow through Gatewell & $56 \%$ & $84 \%$ \\
\hline
\end{tabular}

\subsubsection{Structural Modifications at B2 Intakes - 2001}

Based upon these promising hydraulic model study results, the Portland District made modifications to Unit 15 in the spring of 2001. Intake 15A did not receive a gap-closure device like those installed in Intakes $15 \mathrm{~B}$ and $15 \mathrm{C}$, but other modifications were the same.

The modifications generally have been successful at increasing gatewell slot flow and FGE, but little is known about the effects of the gatewell modifications on gap losses. Most fish guided by an STS pass up into gatewell slots where they find an orifice leading to a bypass channel, but some proportion of the guided flow and fish are lost to the gap that exists between the top end of the STS and the intake ceiling (see red dye trace in Figure 1.2). 


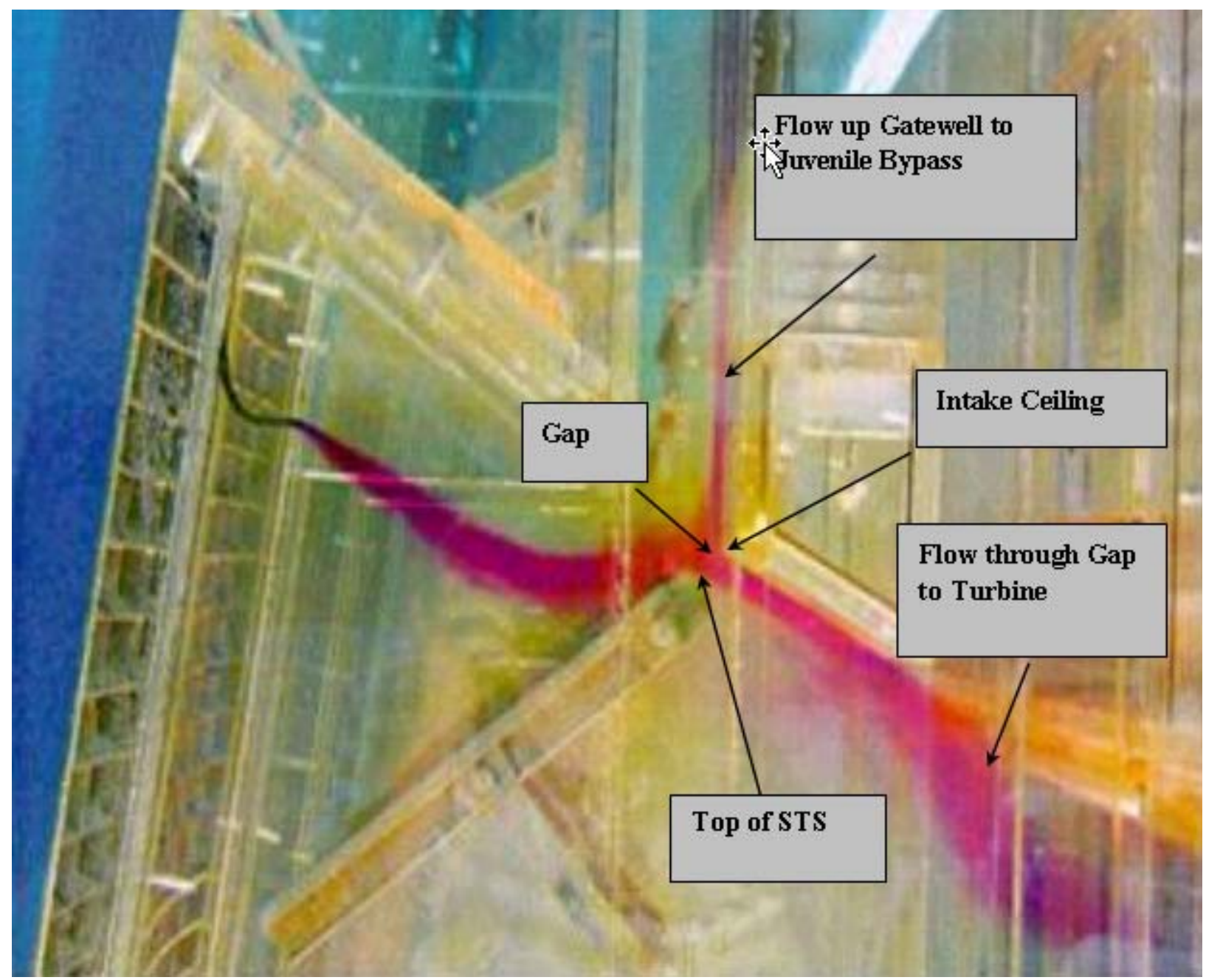

Figure 1.2. Cross-section view of red dye passing through trash racks (at extreme left) into an unmodified intake, gatewell, and Submerged Traveling Screen (STS) gap in a 1:25 scale model at the Engineering Research and Development Center (ERDC), Vicksburg, MS. The relatively high proportion of dye passing through the gap between the top of the STS and the intake ceiling raised concerns for smolt passage. The model was built by the Hydraulics Laboratory at the ERDC. Flow into the intake model is from left to right.

Figure 1.3 shows schematic drawings of the unmodified and unmodified turbine intake. In the modified intake view on the right, the top part of the concrete beam has been removed and the vertical barrier screen (VBS) has been extended downward to increase the screened area and facilitate upward flow. A curved turning vane extending across the intake width also was added to turn flow upward. A gap closure device has been attached to the intake ceiling, covering about 12 inches of the 18-inch gap that exists in an unmodified unit.

In 2001, after the gatewell was modified, fish-guidance efficiency tests were conducted in the 15B gatewell where no TIE was present (Monk et al. 2002). In spring, yearling chinook salmon FGE averaged $71 \%(\mathrm{SE}=2.5$ ), and FGE estimates for steelhead and coho were higher than $80 \%$. These FGE values were the highest measured at B2 since testing began in the early 1980s and were $15 \%$ to $33 \%$ higher than comparable values measured in Unit 15 in 1994. In summer, sub-yearling chinook salmon 
FGE averaged 57\%, which was $17 \%$ higher than earlier measurements. The hydroacoustic estimate of FGE at Intake 15B in spring $2001(70 \%)$ was the highest of any unit sampled at B2. In summer, hydroacoustic FGE was 52\%, slightly lower than the 57\% estimated by Monk et al. (2002) and similar to hydroacoustic FGE estimates for unmodified Units 13 and 14 (Ploskey et al. 2002).

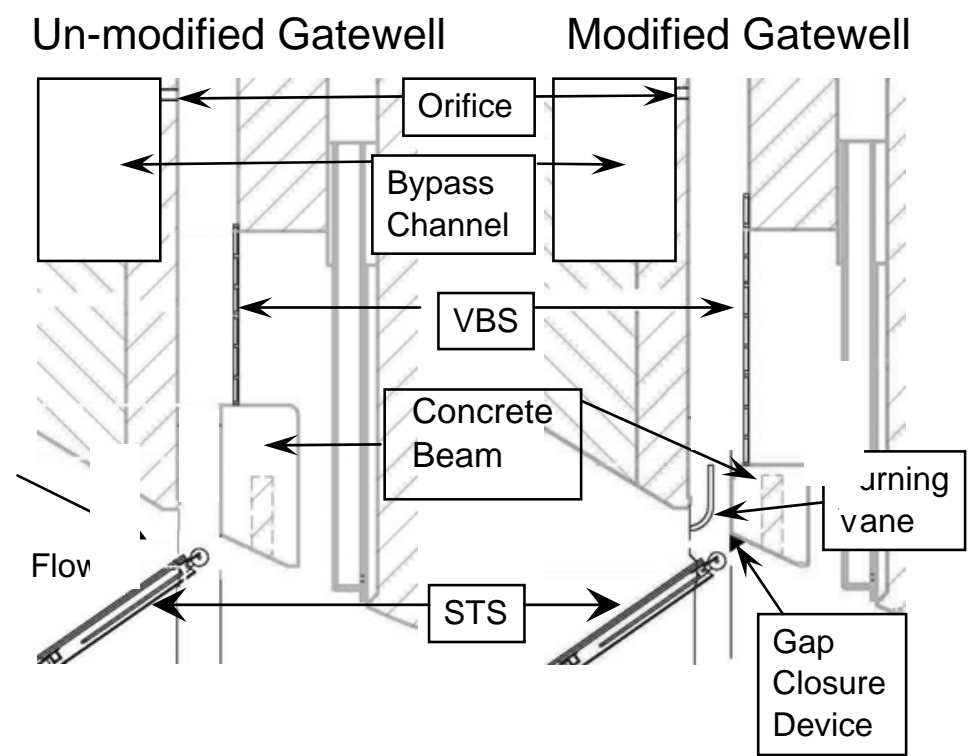

Figure 1.2. Cross-section views of unmodified (left) and modified (right) gatewell slots of B2 intakes. Abbreviations are as follows: VBS = vertical barrier screen; STS = submerged traveling screen. Modified features include the VBS, concrete beam, turning vane, and gap-closure device.

Based on these favorable results, the Portland District decided to make the same modifications to all gatewell slots at Unit 17 on the north end of B2 to see whether similar results could be obtained at intakes with and without TIEs at an off-center unit. Since TIES were installed on every other intake across the powerhouse, odd-numbered intakes have the same configuration (TIES on $\underline{A}$ and $\underline{C}$ intakes but none on $\underline{B}$ intakes). In 2002, FGE tests were conducted in Unit 17 by NOAA Fisheries (Monk et al. In prep.), and all three turbine intake slots were netted to evaluate potential slot effects. Results from spring 2002 indicated that netting estimates of FGE for yearling chinook salmon averaged $47 \%, 67 \%$, and $31 \%$ for the A, B, and C intakes, respectively. Steelhead FGE averaged $49 \%, 54 \%$, and $36 \%$, and coho salmon averaged $51 \%, 71 \%$, and $60 \%$ for the $\mathrm{A}, \mathrm{B}$, and $\mathrm{C}$ intakes, respectively. The FGE estimates among intakes were statistically different for yearling chinook salmon $(\mathrm{p}=0.001)$, but not for steelhead $(\mathrm{p}=$ $0.14)$ or coho salmon $(\mathrm{p}=0.096)$. Although the results from Unit 17 were higher than were those observed in previous studies with the unmodified configuration (36\% in 1994), they were not as high as were those from Unit 15 in 2001 under a similar configuration. Steelhead guidance was lower than expected. Results from summer 2002 indicate that FGE for sub-yearling chinook salmon averaged $47 \%$ and 57\% for the A and B intakes, respectively, which is similar to the 57\% FGE observed in 15B in 2001.

The hydroacoustic evaluation in 2002 produced FGE estimates for Units 15 and 17 that were significantly higher than were those of all other unmodified units at B2, except for unmodified Unit 14 located near the center of the powerhouse in spring and summer (Ploskey et al. 2003). Hydroacoustic FGE estimates based upon nighttime sampling of Unit 17 on the same nights that 1 to 2 hour netting samples were taken by NOAA Fisheries were within $8 \%$ to $12 \%$ of the netting estimates in both seasons (Ploskey et al. 2003). The hydroacoustic estimates were $8 \%$ higher than were the netting estimates at the 
B slot and were $12 \%$ higher than were the netting estimates at the $\mathrm{C}$ slot in spring. They were $8 \%$ lower than netting estimates for the B slot of Unit 17 in summer. Hydroacoustic sampling was not conducted in the A slot during either season, and netting was not done in the $\mathrm{C}$ slot in summer. The $\mathrm{B}$ and $\mathrm{C}$ intakes of B2 units and those intakes between TIES at B2 had significantly higher FGE estimates than did A slots or intakes behind TIES, respectively, probably because $\underline{\mathrm{A}}$ slots have the highest flows and TIEs create vortices that funnel fish down the face of the dam where they enter high in the intake and are guided by the STSs. In 2002, the B slot of Unit 17 had a higher FGE than did the C slot, and this likely was because the B slot was between two TIES.

Results in 2001 and 2002 were encouraging but concerns arose due to the variability in FGE estimates between units and intakes in short- and long-term orifice passage efficiency (OPE) estimates, observed for the first time in Unit 17. Project managers decided that further investigation of fish behavior in the new gatewell environment was warranted prior to a decision to permanently install the new configuration in other turbine intakes. The results from 2002 corroborated the 2001 findings that the gatewell modifications improved the level of fish guidance into the gatewells with little, if any, effect on fish condition over the existing configuration. However, the 2002 results also indicate that FGE varied between units and intakes at B2.

For the STS configuration used since 1985, NMFS gap-net catches as a percent of the number of smolts netted in the gatewell were low, averaging < $2.5 \%$ in spring and $<5 \%$ in summer (Gessel et al. 1986; Monk et al. 1994, 1995, 2002, and In prep.). The "gap-loss" proportion had been thought to be acceptably low until recently when a new sampling tool, the Dual-Frequency Identification Sonar (DIDSON) imaging device, suggested that it might be important. In the spring of 2002, a few nights of sampling with a DIDSON provided preliminary estimates of gap loss (as a percent of guided fish) that were $4 \%$ for modified Intake 17B but $41 \%$ in unmodified Intake 18A. In summer, DIDSON-based estimated gap loss was about $26 \%$ of guided fish in modified Intake $17 \mathrm{C}$ and $27 \%$ in unmodified Intake 13B. Except for the 4\% estimate for modified Intake 17B in spring, the 2002 DIDSON estimates were substantially higher than were the netting estimates (Ploskey et al. 2003), and those differences must be reconciled to understand how much gap loss may be affecting the accuracy of FGE estimates by netting and hydroacoustics.

\subsection{Study Objectives}

This study examined the effect of the gatewell modifications on the proportion of screened ("guided") fish that are lost through the gaps between the tops of the submerged traveling screens and the ceilings of the intakes in one un-modified and two modified turbine units at B2. We used a DIDSON to examine the effect of the gatewell modifications on the gap-lost proportion in two modified turbine units (Units 15 and 17) as compared to that in an unmodified unit (Unit 13) at B2. Unit 13 was chosen as the unmodified control unit since turbine intake extensions were installed on every second intake across the powerhouse. Either odd-numbered or even-numbered units had similar arrangements of TIEs which were present on the $\mathrm{A}$ and $\mathrm{C}$ intakes and absent from the $\mathrm{B}$ intakes of all three units.

We had five objectives to evaluate gap loss at modified and unmodified turbine intakes at B2:

1. Deploy a down-looking DIDSON acoustic imaging device in six modified gatewells (three each at Units 15 and 17) and the three unmodified gatewells of Unit 13 and collect data on proportions of juvenile salmonids moving up into the gatewell and of those that pass through the gaps between the 
tops of the screens and the ceilings of the intakes for three 8-h nighttime periods per intake each season.

2. Test for differences in proportions of gap loss among modified versus unmodified condition, intake position (A, B, or C slots), and presence or absence of a Turbine Intake Extension.

3. Examine samples collected over a 24-h period at one intake in each season for diel trends.

4. Examine samples collected at each of five lateral locations within gatewells to determine the horizontal distribution of gap loss within individual intakes.

5. In spring and summer, sample all intakes of Unit 13 with four underwater infrared-sensitive optical cameras and infrared lights to confirm the presence of fish passing through the gap and the proportion of detected objects that likely were fish.

\subsection{Site Description}

The second powerhouse at Bonneville Dam (Figure 1.4) has eight Kaplan turbines, each with three intakes. In 2003, the Sluice Chute at the south end of B2 was closed all year, so fish passage was through turbines or the juvenile bypass system (JBS). Smolts enter the JBS after they encounter screens in the upper part of turbine intakes and are diverted to gatewell slots and orifices opening to a bypass channel unless they are lost to the gap between the top of the STS and the intake ceiling.

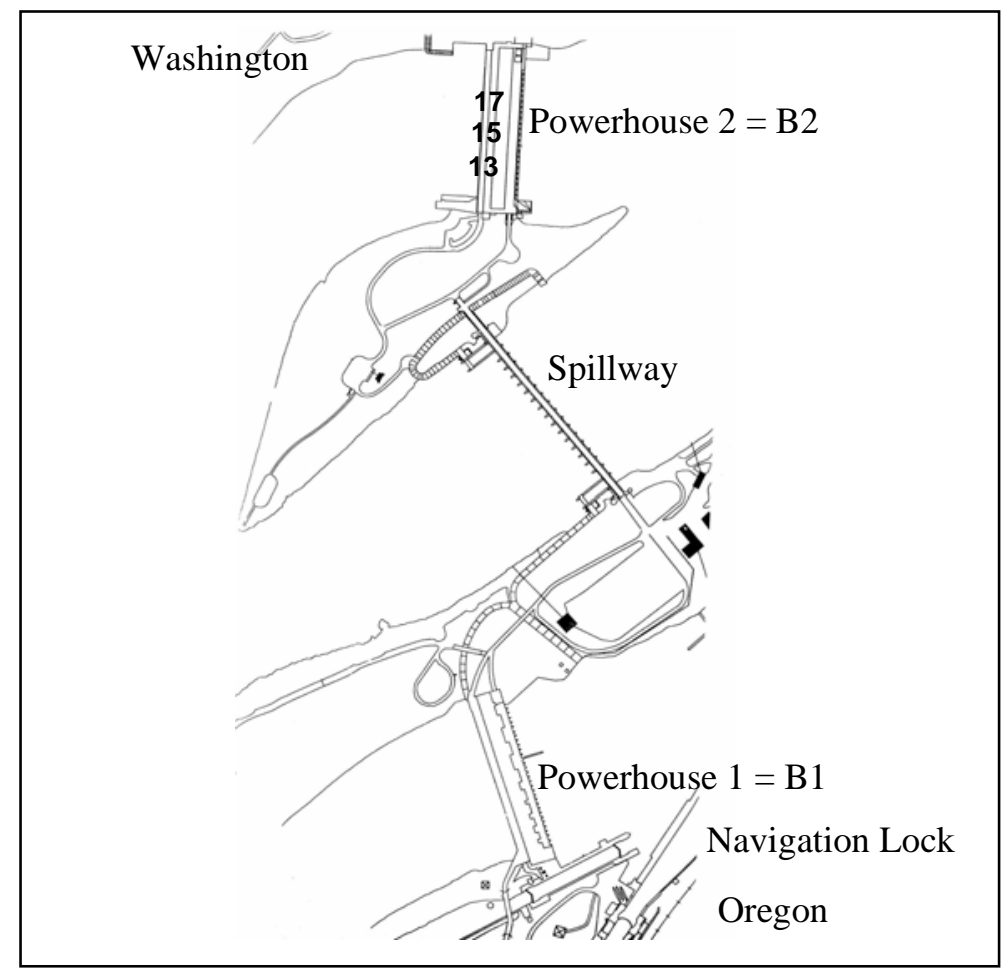

Figure 1.4. Plan View of the Bonneville Dam Project Showing the Location of Powerhouse 2 and the approximate location of Units 13,15 , and 17, which are three of the eight turbine units in $\mathrm{B} 2$. 


\subsection{Overview of this Report}

Chapter 1 provides background and introduction. Chapter 2 describes methods used. Chapter 3 reports results. Chapter 4 is a discussion. Chapter 5 lists conclusions and recommendations. Chapter 6 is references. 


\subsection{Methods}

\subsection{Approach}

Although the netting studies carried out by NOAA Fisheries at B2 and elsewhere have captured very few "gap lost" fish in the past, our early sampling with the DIDSON and hydraulic model studies suggested that actual gap loss may be somewhat higher. The present study was undertaken in an effort to verify the earlier DIDSON findings and to explore further the effects of turbine intake modifications on gap loss at B2 intakes. To verify the earlier DIDSON-based estimates, we sampled inside the slots of unmodified intakes with an array of four infrared-sensitive cameras with infrared lights to determine what portion of objects passing through the gap were not fish. When non-fish objects were found to make up a substantial portion of the gap-passed objects appearing in the video record, we developed filtering criteria, based on total length of targets, range at first appearance, and motion to eliminate non-fish targets from DIDSON counts. We compared those filtered counts against unfiltered counts adjusted downward by multiplying by the proportion of non-fish in the video data. DIDSON filters were considered to be optimized when concordant estimates were obtained by the two methods. Filtered estimates for modified and unmodified units were compared using analysis of variance (ANOVA), but we based the assessment of among-intake differences on visual inspection of means and $95 \%$ confidence intervals because three nights of sampling per intake did not provide adequate statistical power for a formal test. Twenty-four hour data sets were collected and analyzed for diel trends in gap loss at a modified intake.

\subsection{Equipment}

The gaps between the tops of the STSs and the intake ceilings in each of the three unmodified intakes of Unit 13 were sampled with four Inuktun FireflEYE (sic) optical cameras. The cameras were blackand-white units, with a 2.9-mm fixed focus lens and a resolution of 430 lines of NTSC video, a light sensitivity of $0.03 \mathrm{lux}$, and a field of view of about 60 degrees in the horizontal plane. Outland Technology Inc. model UWL-200 underwater lights with infrared-transparent filters (which blocked visible light) were deployed adjacent to each camera to provide light that was visible to the cameras but not to fish. Video images from two cameras were recorded to two separate Panasonic AG-DV2000 digital videotape recorders, and images from the other two cameras were recorded on separate Panasonic Hi- 8 videotape recorders. The capacities of Hi-8 and digital tapes were about 2 and 3 hours, respectively.

We used a Dual-Frequency Identification Sonar (DIDSON) acoustic imaging device to record juvenile salmonids moving up into the gatewells and through the gaps between the tops of the STSs and the ceilings of the intakes. The DIDSON was developed by the Applied Physics Laboratory (APL) at the University of Washington for the Space and Naval Warfare Systems Center harbor surveillance program (Belcher et al. 1999). It can image objects out to 48 meters and can provide near-video-quality images to identify objects out to about 12 meters. The DIDSON was designed to bridge the gap between existing sonar, which can detect acoustic targets at long ranges but cannot record the shapes or sizes of targets, and optical systems, which with sufficient light can image nearby fish in clear water but are limited by low light levels or turbidity. In an unconfined environment, the images within $9 \mathrm{~m}$ of the device are so clear that one can see fish undulating as they swim and can tell the head from the tail. The DIDSON is not as sensitive to entrained air as are the 6- or 10-degree beams that are typically used for hydroacoustic sampling so it can be used to sample in a gatewell slot. In such a confined space the frame rate is limited to 8 to 10 frames / s. 


\subsection{Equipment Deployment and Sampling Schemes}

\subsubsection{Sampling Schedule}

The sampling schedule is presented in Table 2.1. We sampled the modified intakes in Units 15 and 17 with the DIDSON. We sampled the unmodified intakes of Unit 13 with the DIDSON and optical cameras

Table 2.1. Spring and Summer 2003 Sampling Schedule. Modified intakes A, B, and C of Units 15 and 17 sampled with DIDSON only; unmodified intakes A, B, and C of Unit 13 sampled with DIDSON and optical cameras.

\begin{tabular}{|c|c|c|c|c|c|c|c|}
\hline \multirow[b]{2}{*}{ Date } & \multicolumn{2}{|c|}{ Spring } & \multirow[b]{2}{*}{$\begin{array}{c}\text { Presence } \\
\text { of TIE }\end{array}$} & \multirow[b]{2}{*}{ Date } & \multicolumn{2}{|c|}{ Summer } & \multirow[b]{2}{*}{$\begin{array}{c}\text { Presence } \\
\text { of TIE }\end{array}$} \\
\hline & $\begin{array}{c}\text { Intake } \\
\text { Sampled } \\
\text { Overnight }\end{array}$ & $\begin{array}{c}\text { Presence of } \\
\text { Gap Closure } \\
\text { Device }\end{array}$ & & & $\begin{array}{c}\text { Intake } \\
\text { Sampled } \\
\text { Overnight }\end{array}$ & $\begin{array}{c}\text { Presence of } \\
\text { Gap Closure } \\
\text { Device }\end{array}$ & \\
\hline 1-May & $\overline{17 \mathrm{~B}}$ & Closure & $\overline{\text { TIE }}$ & 12-Jun & $113 C^{*}$ & "No Closure & 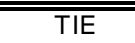 \\
\hline 2-May & $"$ & $"$ & $"$ & 13-Jun & $"$ & $"$ & $"$ \\
\hline 3-May & $"$ & $"$ & $"$ & 14-Jun & $"$ & $"$ & $"$ \\
\hline 4-May & & & & 15-Jun & & & \\
\hline 5-May & $17 \mathrm{~A}$ & Closure & No TIE & 16-Jun & $13 B^{*}$ & No Closure & No TIE \\
\hline 6-May & $"$ & $"$ & $"$ & 17-Jun & $"$ & " & $"$ \\
\hline 7-May & $"$ & $"$ & $"$ & 18-Jun & $"$ & $"$ & $"$ \\
\hline 8-May & $17 \mathrm{C}$ & Closure & TIE & 19-Jun & $13 A^{*}$ & No Closure & TIE \\
\hline 9-May & $"$ & $"$ & $"$ & 20-Jun & " & $"$ & $"$ \\
\hline 10-May & $"$ & $"$ & $"$ & 21-Jun & $"$ & $"$ & $"$ \\
\hline 11-May & & & & 22-Jun & & & \\
\hline 12-May & $15 \mathrm{C}$ & Closure & TIE & 23-Jun & $15 B$ & Closure & TIE \\
\hline 13-May & $"$ & " & $"$ & 24-Jun & $"$ & $"$ & $"$ \\
\hline 14-May & $"$ & $"$ & $"$ & 25-Jun & $"$ & $"$ & $"$ \\
\hline 15-May & $15 \mathrm{~A}$ & No Closure & No TIE & 26-Jun & $15 \mathrm{~A}$ & No Closure & NO TIE \\
\hline 16-May & & $"$ & $"$ & 27-Jun & $"$ & $"$ & \\
\hline 17-May & & $"$ & $"$ & 28-Jun & $"$ & $"$ & \\
\hline 18-May & & & & 29-Jun & & & \\
\hline 19-May & $15 B$ & Closure & TIE & 30-Jun & $15 \mathrm{C}$ & Closure & TIE \\
\hline 20-May & $"$ & $"$ & $"$ & 1-Jul & $"$ & $"$ & $"$ \\
\hline 21-May & $"$ & $"$ & $"$ & 2-Jul & $"$ & $"$ & $"$ \\
\hline 22-May & $13 C^{*}$ & No Closure & TIE & 3-Jul & & & \\
\hline 23-May & $"$ & $"$ & $"$ & 4-Jul & & & \\
\hline 24-May & $"$ & $"$ & $"$ & 5-Jul & & & \\
\hline 25-May & & & & 6-Jul & & & \\
\hline 26-May & Memorial Day & & & 7-Jul & 17B & Closure & TIE \\
\hline 27-May & $13 B^{*}$ & No Closure & No TIE & 8-Jul & $"$ & $"$ & $"$ \\
\hline 28-May & $"$ & $"$ & $"$ & 9-Jul & $"$ & $"$ & $"$ \\
\hline 29-May & $"$ & $"$ & $"$ & 10-Jul & $17 \mathrm{~A}$ & Closure & No TIE \\
\hline 30-May & $13 A^{*}$ & No Closure & TIE & 11-Jul & $"$ & $"$ & $"$ \\
\hline 31-May & $"$ & $"$ & $"$ & 12-Jul & $"$ & & $"$ \\
\hline \multirow[t]{7}{*}{ 1-Jun } & $"$ & $"$ & $"$ & 13-Jul & & & \\
\hline & & & & 14-Jul & $17 \mathrm{C}$ & Closure & TIE \\
\hline & & & & 15-Jul & $"$ & & $"$ \\
\hline & & & & 16-Jul & $"$ & & $"$ \\
\hline & & & & 17-Jul & $17 \mathrm{C}$ & Closure & NO TIES \\
\hline & & & & 18-Jul & $17 \mathrm{~B}$ & " & NO TIES \\
\hline & & & & 19-Jul & $17 \mathrm{~A}$ & $"$ & NO TIES \\
\hline
\end{tabular}




\subsubsection{Sampling with Optical Cameras at Unmodified Unit 13}

One STS was outfitted with optical cameras and infrared lights, which were deployed on steel beams extending about 9 inches above the top of the STS on the downstream side and aimed horizontally across the top of the STS (Figure 2.1). That STS, with cameras and infrared lights attached, was moved to whichever of the three Unit 13 intakes were to be sampled at a given time and similar STSs without cameras were installed in all remaining turbine intakes.

The gaps between the tops of the STSs and the intake ceilings of unmodified Unit 13 were 18 to 20 inches, according to stick breakage tests conducted during preliminary screen deployments. We attached four 1x2-inch boards to the downstream side of the STS with varying lengths $(14,16,18$, and 20 inches) extending above the top of the STS. When the STS was deployed and rotated upstream $55^{\circ}$ from vertical, only the 20-inch board was broken by contacting the intake ceiling so we knew cameras and lights located 9 inches above the top of the STS would be about halfway between the top of the STS and the intake ceiling when the STS was deployed.

The STS with mounted cameras and lights was deployed for three nights in each of the three intakes of Unit 13 in spring and in summer. Video data were recorded to tape each night. A full rigging crew and several biologists were required to move the STS and associated cables from intake to intake, so we sampled each intake for three consecutive nights to minimize the number of moves required. We randomized the order in which the three intakes of each unit were sampled.

Videotapes were processed manually by viewing images from each camera and classifying objects detected moving through the gap as either possible fish or non-fish objects. We did not expand fish counts from the range of detection to the maximum range that could have been sampled because the visibility was so poor (less than ca. 10 inches).

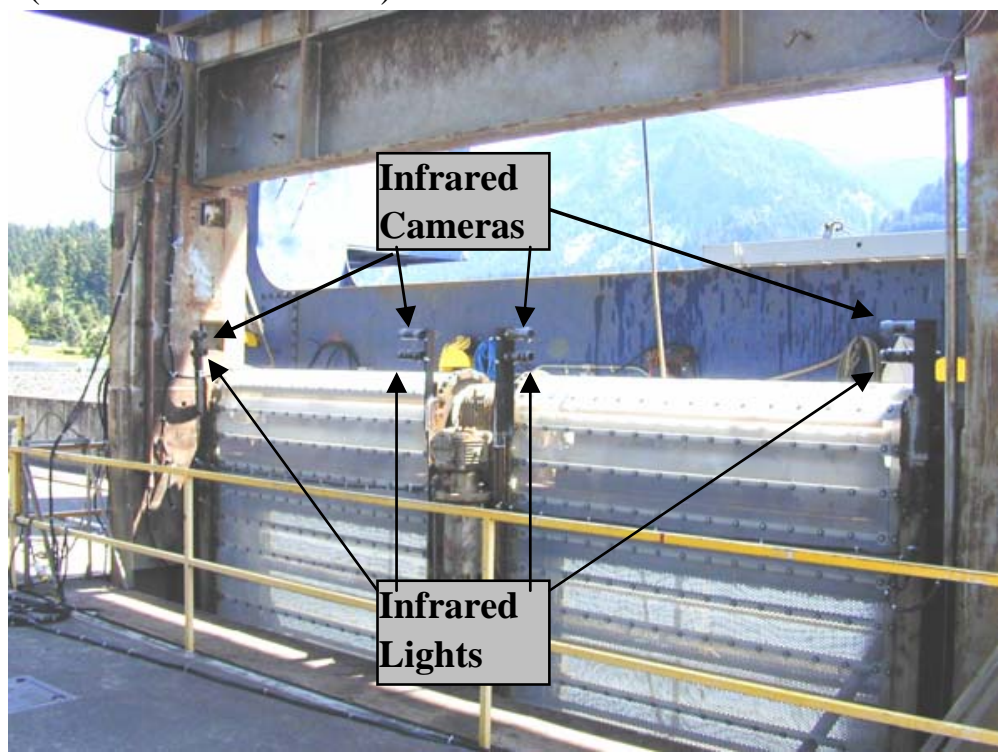

Figure 2.1. Four pairs of optical cameras and associated infrared lights were mounted on steel angle iron at the top of an STS at unmodified Unit 13. The cameras were located 9 inches above the top of the STS and aimed horizontally across the top of the STS so that they would be in the middle of the gap when the STS was deployed in an intake. 


\subsubsection{Sampling with the DIDSON}

The DIDSON was attached to a mounting plate that was moved along a 20-ft-long horizontal beam by a stepper motor so that samples could be taken from five lateral locations across the gatewell when operators were present to provide remote control of the DIDSON's lateral position by way of the stepper motor (Figure 2.2). The stepper motor was controlled by custom-designed software on a computer through a serial communication port. Stepper motor feedback to the computer provided position information, and positions were verified by five position sensors located along the beam that illuminated position indicator lights in the equipment trailer.

The DIDSON was used to record images of fish passing up into the gatewell and through the gap for 8-h on three successive nights in every intake of Units 13,15, and 17 (i.e., nine intakes $\mathrm{x}$ three nights $=27$ nights each season). During nighttime sampling, the DIDSON was moved among five lateral positions at 30-minute intervals. The images were also recorded during one 24 -h period in each season to provide diel information about gap loss, with the camera left in the center of the gatewell and not moved among the five locations on the beam during 16 of the 24 hours. The imaging rate ranged from nine to 10 frames / s depending upon the amount of entrained air entering the gatewell slot.

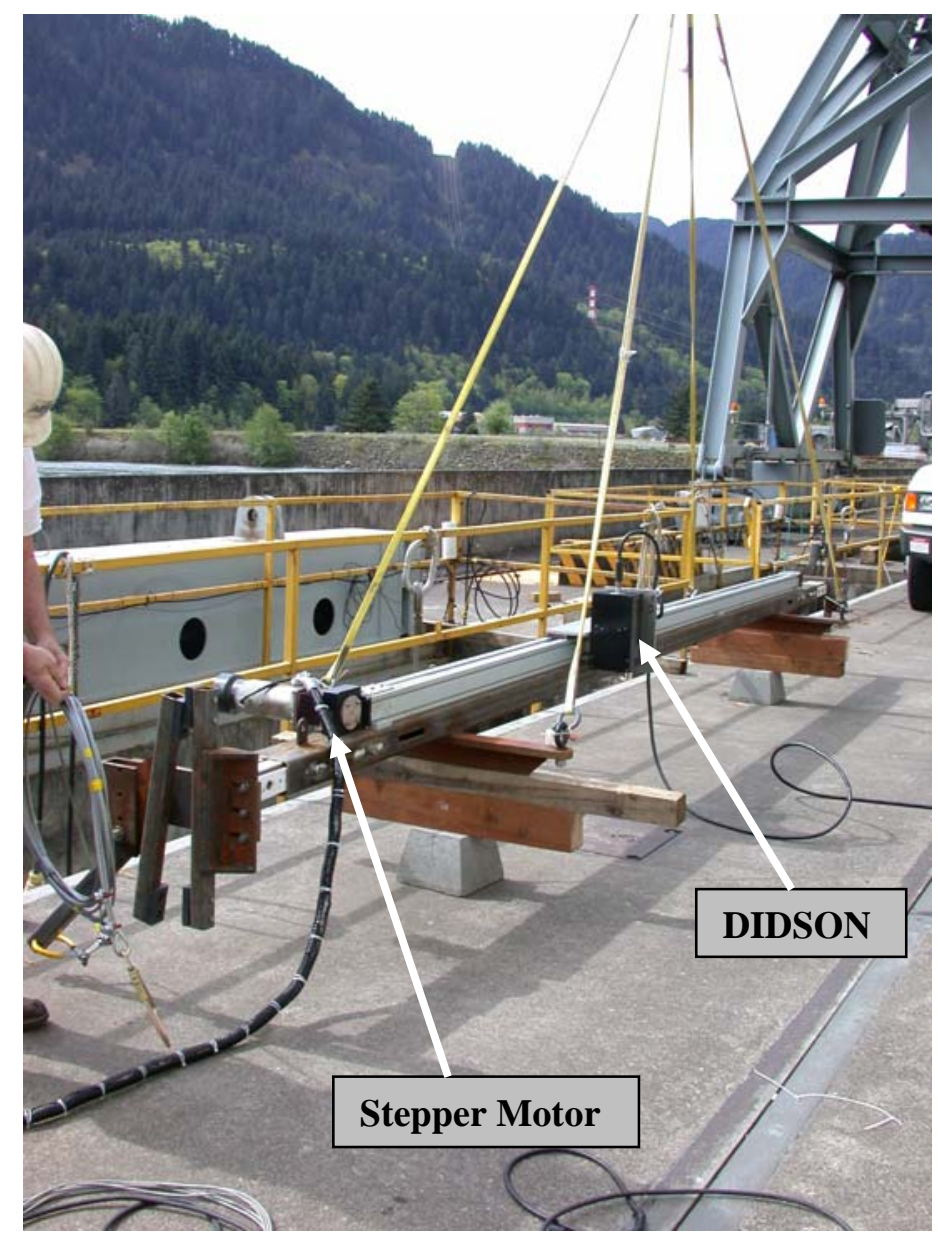

Figure 2.2. Beam used to deploy the DIDSON in gatewell slots of intakes in unmodified Unit 13 and in modified Units 15 and 17 . The stepper motor that moved the DIDSON along the beam is on the left and the moving plate with the DIDSON attached is in the middle of the beam. The beam was deployed by riggers using the turbine-intake-extension crane. 
The DIDSON was aimed downward in the gatewell slot, and the fan of $960.3^{\circ}$-wide and $12^{\circ}$-deep beams was oriented in an upstream-downstream direction (Figure 2.3). The DIDSON images fish in two dimensions, either moving toward or away from the device (up or down) or laterally across the array of beams. Water flow is from right to left and splits just upstream of the intake ceiling and gap. The DIDSON produces images that look like medical ultrasound images as shown in Figure 2.4.

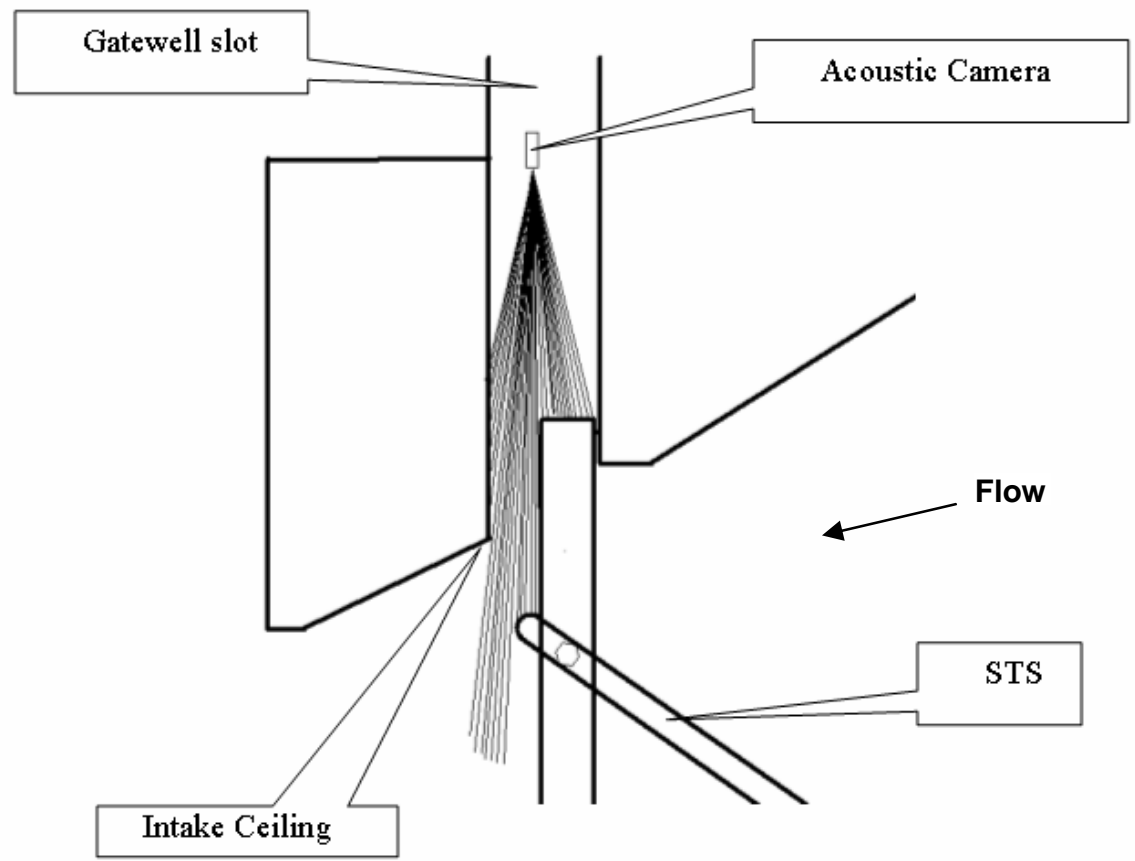

Figure 2.3. Cross-sectional diagram of an unmodified gatewell slot of Unit 13 at B2 showing the DIDSON deployment. Flow would be entering the intake from the right side.

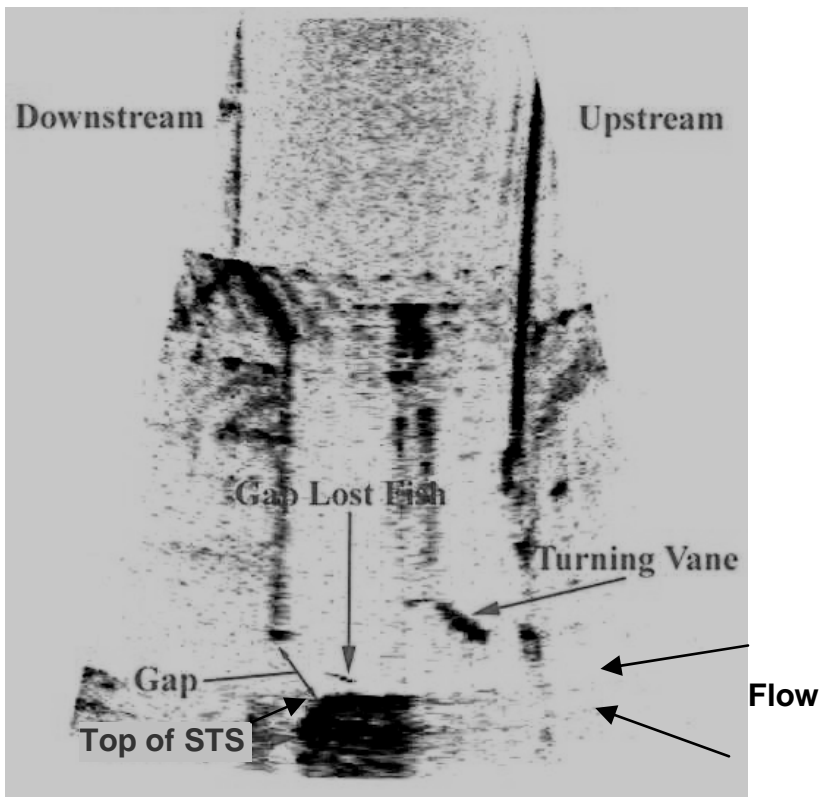

Figure 2.4. Image from the DIDSON Deployed in Modified Gatewell $17 \mathrm{C}$ of B2. Flow is moving from right to left below the tip of the turning vane and upward above the tip of the vane. 
The preliminary method for processing DIDSON data was the same as that used in 2002. We processed all spring 2003 data by viewing native DIDSON files (ddf format) and counting the number of fish-shaped images observed moving up into the gatewell or through the STS gap. We did not set a minimum for the number of frames in which a fish needed to be detected, so even single and two-frame images of linear objects passing through the gap were accepted as fish. Images of gatewell-bound fish were captured in multiple frames (5 to 30) compared to the 1 to 2 frames available to detect most fish passing through the STS gap. We recorded only the filename, first frame and range of detection and the fate of every fish (i.e., gatewell or gap lost).

In the video data some objects were clearly classifiable as fish and others were classified as possible fish due to their shape, scale shine, or other fish-like appearance. However, many objects either clearly were not fish or had no fish-like characteristics. After preliminary processing of optical-camera data and discovering that only about $28.6 \%$ of detected objects in the STS gap could have been fish, we had to determine exactly what the DIDSON was capable of imaging. In a few days of testing the capabilities of the DIDSON in a laboratory tank, we found that it not only readily imaged fish but also waterlogged (sinking) sticks and pieces of aquatic macrophytes, other debris, and even the fishing line used to move these object through the tank. Operating at $1.8 \mathrm{MHz}$, the DIDSON actually produces images of the surfaces of objects rather than reducing a target to a sound scattering center, like conventional hydroacoustics. The positive result is that the image does not depend on a strong reflection from a fish's gas bladder, and a fish-like image can be produced. The negative result is that some objects that would not provide strong echoes for conventional hydroacoustics, such as waterlogged sticks, also produce images that can be confused with fish images. Unfortunately such objects are plentiful rolling up a STS and passing through the gap.

After determining that the DIDSON could image waterlogged sticks and other debris, we spent several weeks reviewing sequences of gap-loss events in DIDSON movies to identify objects that obviously were fish. We assembled a subset of spring gap-loss events in which objects were clearly swimming, as evidenced by body undulation from frame to frame, holding position in flow, or crossing streamlines of flow. Flow patterns and streamlines are often distinguishable by the movement of small particles or bubbles embedded in the flow. Most of the fish gap passage events were from unmodified Unit 13, but there were some from modified intakes as well.

We also assembled a data set of gap-loss events that very likely did not include fish because images of objects passing through the gap were not undulating and moved with stream lines of flow at a rate similar to images of adjacent small particles entrained in flow. This data set was important in identifying characteristics of non-fish objects so that they could be discriminated from fish.

We analyzed both subsets of images to identify location and frame-count characteristics associated with passage of known fish and non-fish objects and were able to develop a set of filtering criteria for processing data. Undulating objects and objects crossing flow lines in gaps of A and B intakes were usually detected in five or more frames, whereas fish in gaps of $\mathrm{C}$ intakes usually were detected in six or more frames. Intake, gatewell, and gap flows are higher in A and B intakes than they are in $\underline{\mathrm{C}}$ intakes, and objects that were not undulating or crossing stream lines usually were detected in < five frames in A and B intakes and < six frames in C intakes. In reprocessing spring 2003 data and processing summer data, we deleted observations that met the following criteria:

1. Gatewell-bound objects first detected at ranges $<3 \mathrm{~m}$ from the DIDSON or in $<$ three frames. Fish within $3 \mathrm{~m}$ of the DIDSON and more than $2 \mathrm{~m}$ above the top of the screen had a higher probability of being re-circulated through the field of view and counted multiple times than fish detected within $2 \mathrm{~m}$ of the top of the screen. 
2. Gap-lost objects that were not undulating or crossing stream lines or that were detected in $<4$ frames in A or B intakes or in $<5$ frames in $\mathrm{C}$ intakes.

3. Maximum target length $<70 \mathrm{~mm}$ and $>305 \mathrm{~mm}$ in spring or $<70 \mathrm{~mm}$ and $>150 \mathrm{~mm}$ in summer.

We assumed that filtering criteria were most appropriate when filtered estimates of gap loss at Unit 13 were closest to the unfiltered estimates from the same data that had been adjusted by multiplying unfiltered estimates by the fish fraction (possible fish / possible fish + non-fish) detected by optical cameras. This comparison was only possible because spring 2003 DIDSON data were processed initially without regard to the number of detection frames. Therefore, we were able to expand unfiltered counts (as described below) and then multiply by the fraction of gap-lost objects that could have been fish in optical camera data to obtain an independent estimate of gap loss for Unit 13.

Subsequent reprocessing of spring data and processing of summer data became much more complicated and time consuming than processing with simpler criteria. The list of items to record per event increased from just filename, first frame and range of detection, to include the number of frames, frames with images, shape, proximity to the STS (on or above the STS), whether undulation was observed, maximum length, and a comment. This more careful examination and classification of the DIDSON targets limited the number of hours of data that could be reasonably processed from each night. As we began to reprocess spring data, we realized that manual processing of all acquired data would be impossible without a four-fold increase in staff. Therefore, we tried to base nightly estimates of gap-loss percent on at least 100 detections in the gatewell and gap. This approach allowed us to obtain estimates within study resources but prevented us from processing data from more than three or four of the five horizontal positions each night. As a result, gap-loss estimates for individual intakes include some unknown bias because one or two of the five positions were not processed each night, although the unprocessed positions varied among intakes and nights because we randomized the starting position each night.

We expanded the count of every fish using the following equation:

$$
E C=\frac{G W}{2[F R \cdot T A N(12 / 2)]}
$$

where $\mathrm{EC}=$ expanded count, $\mathrm{GW}=$ gatewell width $(6.1 \mathrm{~m}), \mathrm{FR}=$ first range of detection $(\mathrm{m})$, TAN is the tangent, and $12^{\circ}$ degrees is the depth angle of each of the $960.3^{\circ}$-wide acoustic beams with range relative to GW. The expansion increased the count of fish in the gatewell fraction relative to the gap-lost fraction of the total guided passage because gap-lost fish were detected at slightly greater range than were fish moving up into the gatewell.

The gap-loss proportion was calculated as follows:

$$
G L P=\frac{\text { Gap }}{\text { Gap }+ \text { Gatewell }}
$$

where GLP = gap-loss proportion, Gap = gap-loss passage, and Gatewell = gatewell passage.

\subsection{Statistical Analysis}

We compared estimates of gap-loss proportions among intakes and among units by calculating, graphing, and visually comparing means and overlap of $95 \%$ confidence intervals. For each season, means and 95\% confidence intervals were calculated from the three nights of sampling at each intake and from the nine nights of sampling at each unit. With only three samples per intake, there were insufficient 
samples to compare gap loss proportions among intakes with and without TIES. We used analysis of variance (ANOVA) to compare gap loss estimates made during high- and low-discharge conditions in summer, when Unit 17 was operated for three nights at the lower end of its one percent efficiency curve and for four nights at the high end of that range.

\subsection{Dam Operations}

Hourly operations data were provided by Tim Darland of the Bonneville Dam Project. These data were used to determine whether turbine discharge varied significantly among units and seasons and to examine seasonal and daily changes in B2 forebay elevations. 


\subsection{Results}

\subsection{Turbine Operations and Forebay Elevation}

The within-day ranges in daily turbine discharges were quite large, often exceeding the range in mean daily discharge over the course of the study (Figure 3.1). The two modified turbines (Units 15 and 17) were run at the lower end of the one percent efficiency range in spring to reduce strain on the fine mesh vertical barrier screens, but the lower discharge is only noticeable for Unit 17 before Julian day 142 (May 22).

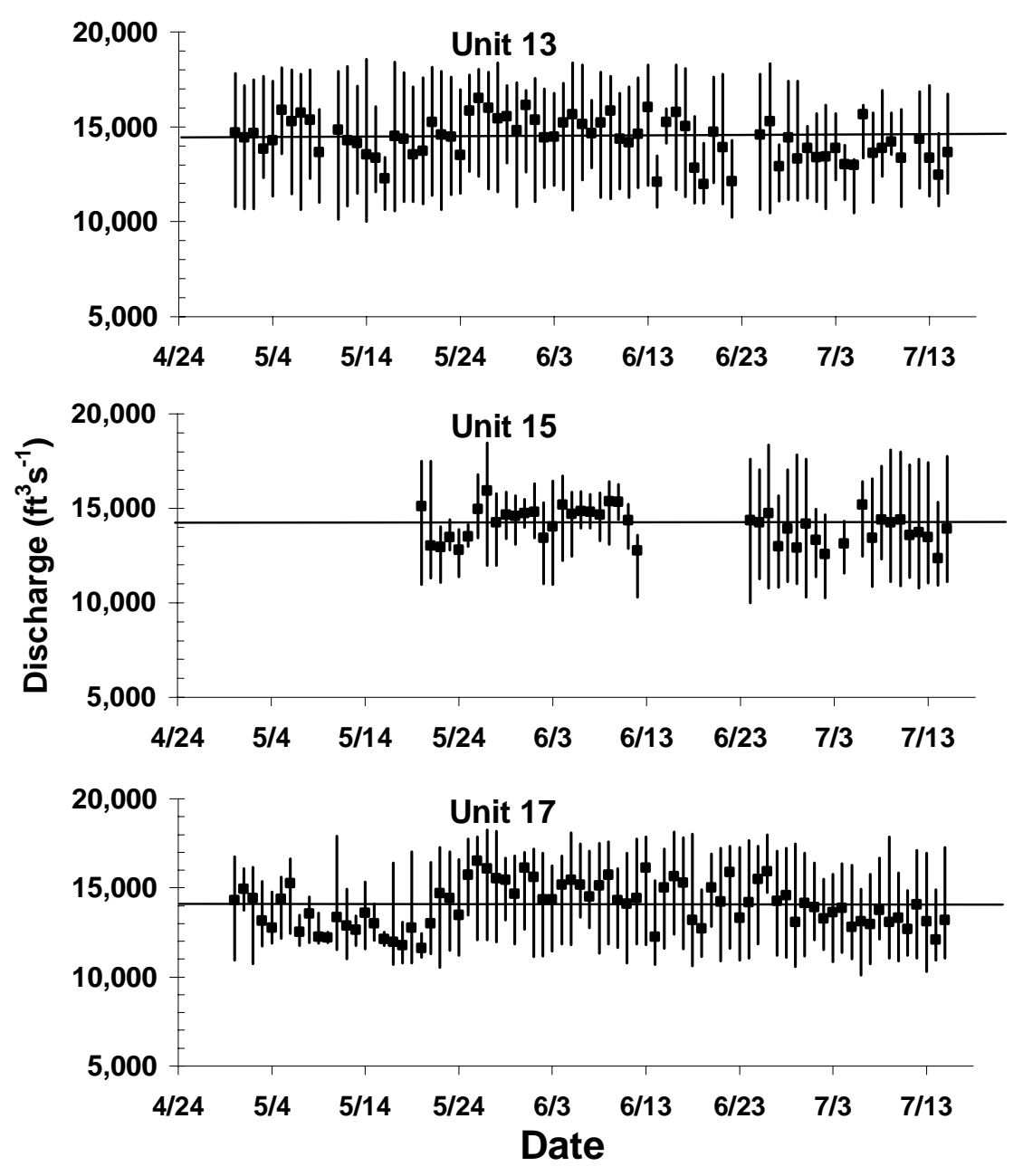

Figure 3.1. Plots of the mean and range in discharge by date for unmodified Unit 13 and modified Units 15 and 17 in spring and summer 2003. June 3rd roughly divides the spring and summer seasons. Squares depict daily averages and vertical bars indicate the range in discharge each day. Horizontal lines represent the average discharge for the hours sampled.

The B2 forebay surface elevation varied by as much as $3 \mathrm{ft}$ each day (Figure 3.2), and there usually was a consistent pattern within days (Figure 3.3). The diel evaluation of gap loss began at midnight on 
May 17, 2003, when forebay surface elevation was $74.2 \mathrm{ft}$ mean sea level (MSL). Forebay surface elevation generally increased from 0000 hours through 1300 hours when it peaked at $75.2 \mathrm{ft}$ and then declined from 1300 hours through 2045 hours when it reached the minimum of $73.5 \mathrm{ft}$ for the day.

\section{Forebay}

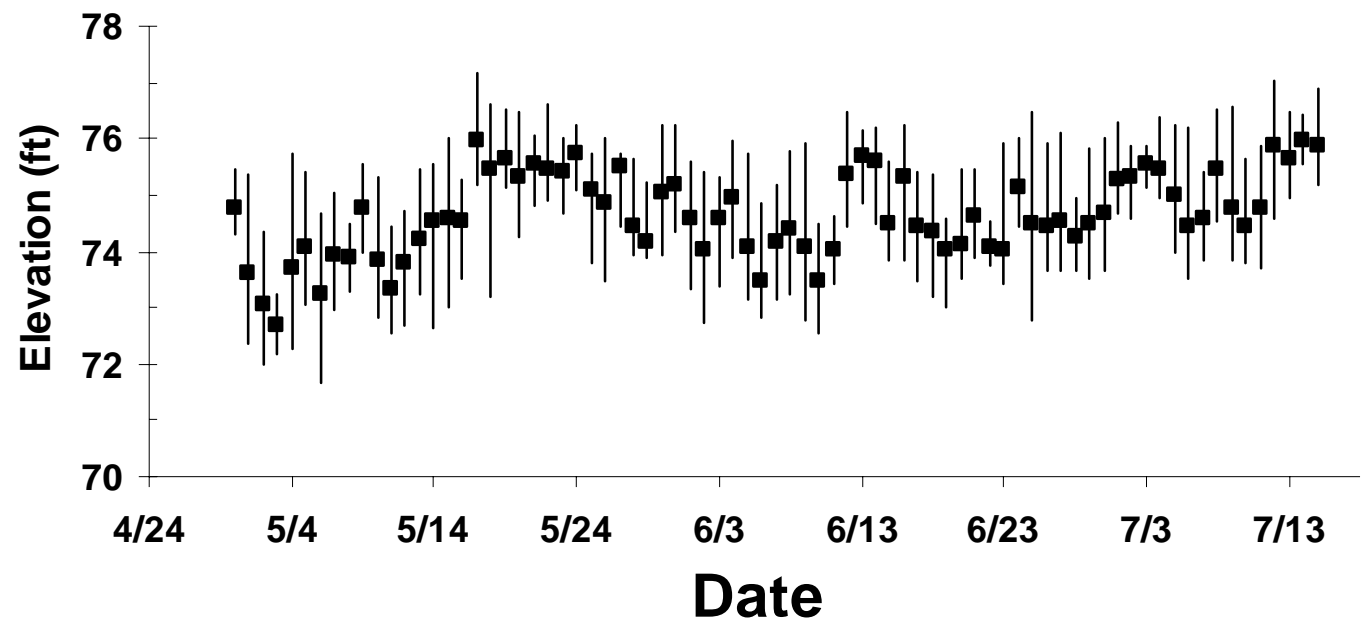

Figure 3.2. Plot of the mean and range in forebay elevation at $B 2$ in spring and summer 2003 . June $3^{\text {rd }}$ roughly divides the spring and summer migration seasons. Squares depict daily averages and vertical bars indicate the range in forebay surface elevation each day.

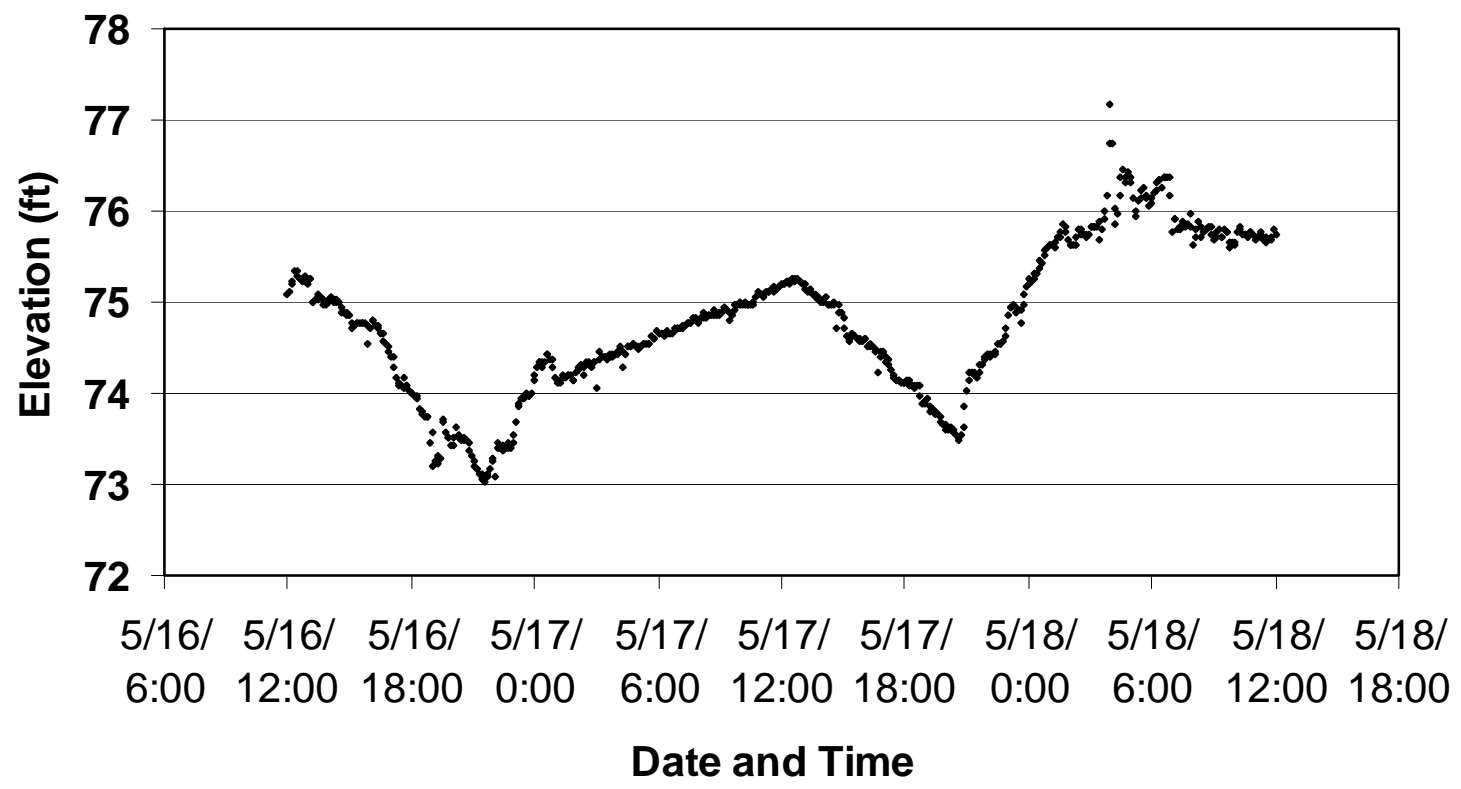

Figure 3.3. Plot of the $\mathrm{B} 2$ forebay elevation by 5 -minute interval over 2 days. These elevation data were provided by the Project. Diel sampling with the DIDSON was conducted from midnight on May 17, 2003 until midnight on May 18. 


\subsection{Optical Cameras in Unit 13}

The data from video camera sampling was only used to estimate the proportion of all objects that could have been fish because camera coverage of the gap was such a small fraction of the total width that we were uncomfortable expanding detections to the entire gap. The maximum range of the field of view of four optical cameras deployed in STS gaps of intakes of unmodified Unit 13 was quite short (less than 10 inches) according to observations made during video processing and measurements made after the STS was retrieved. When deployed and sampling, the top of the STS and bottom of the intake ceiling were never visible in the field of view of any camera. However, when the STS was brought out of the water to the Elevation 90 deck, the fabric of the STS surface was clearly visible at a diagonal range of about 14 inches, which means that the camera likely could not detect objects that were more than about 10 inches in front of them. Therefore, a single camera was only sampling about $5 \%$ of the gap width. In addition, only two of four infrared lights functioned continuously so the video from two of the four cameras usually was unusable.

Of all objects detected in the field of view of the optical cameras, the percentage classified as possible fish was only $33.6 \%$ in spring and $13.2 \%$ in summer. The remaining objects were classified as sticks, pieces of macrophytes, leaves, or other debris. Macrophytes made up 5\% of the detections in spring (most were detected in late May), but constituted $48 \%$ of all detections in summer. The classification of objects near the maximum range of detection was uncertain at best. Proportions were based upon all samples collected in spring and summer because so few objects were detected in the fields of view of the optical cameras.

\subsection{DIDSON Sampling}

Preliminary estimates of gap-loss percent based on unfiltered expanded counts for unmodified intakes were high in both 2002 and 2003 (Figure 3.4). However, multiplying those estimates by the 2003 fraction of optical camera detections that could have been fish reduced the unfiltered estimates to within $3 \%$ to $6 \%$ of filtered estimates for Unit 13 intakes in 2003 (Table 3.1).
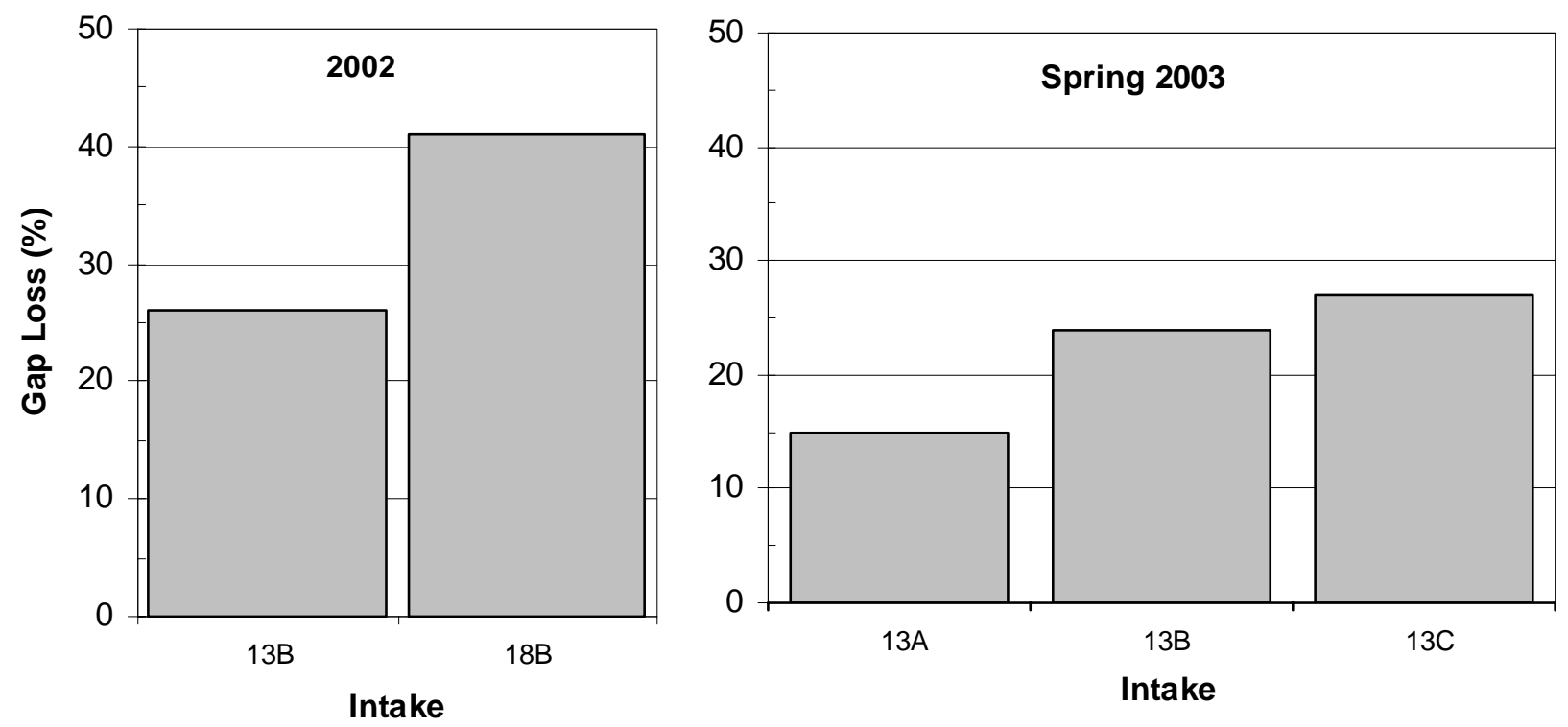

Figure 3.4. Bar charts showing unfiltered gap-loss percentages in unmodified intakes of Unit 13 in spring 2003 and in 2002. 
Table 3.1. Estimates of gap losses in spring expressed as a percent of gatewell and gap-loss passage by three methods: (1) unfiltered counts, (2) unfiltered counts adjusted by the fraction of fish detected by optical cameras in the gap, (3) and filtered counts. Summer 2003 data were only processed by the filtering method and therefore are not included in the table.

\begin{tabular}{|l|c|c|c|c|}
\hline $\begin{array}{c}\text { Season, } \\
\text { Year }\end{array}$ & $\begin{array}{c}\text { Unmodified } \\
\text { Intake }\end{array}$ & $\begin{array}{c}\text { Unfiltered } \\
\text { Estimate (\%) }\end{array}$ & $\begin{array}{c}\text { Adjusted } \\
\text { Unfiltered } \\
\text { Estimate }^{\text {a }} \text { (\%) }\end{array}$ & $\begin{array}{c}\text { Filtered } \\
\text { Estimate }^{\mathbf{b}} \\
\text { (\%) }\end{array}$ \\
\hline Spring 2002 & $18 \mathrm{~A}$ & 41 & 13.8 & N/A \\
\hline Spring 2003 & $13 \mathrm{~A}$ & 15 & 5.0 & 8.1 \\
\hline Spring 2003 & $13 \mathrm{~B}$ & 24 & 8.1 & 13.6 \\
\hline Spring 2003 & $13 \mathrm{C}$ & 27 & 9.1 & 12.0 \\
\hline $\begin{array}{l}\text { a Unfiltered estimate } \times \text { fish fraction in optical cameras in the same season in 2003 } \\
\text { b Only available for 2003 data because 2002 data require reprocessing to allow filtering }\end{array}$ \\
\hline
\end{tabular}

A plot of mean gap loss of filtered data ( $\mathrm{N}=3$ nights) by intake sampled in spring 2003 (Figure 3.5) suggests that at least two of the three unmodified intakes at Unit 13 had higher losses than all other

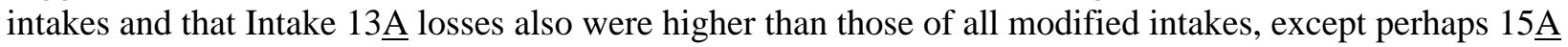
(Figure 3.5). Intake 15스 had all gatewell modifications to increase flow up the slot except for a gapclosure device.

\section{DIDSON-based Estimates in Spring}

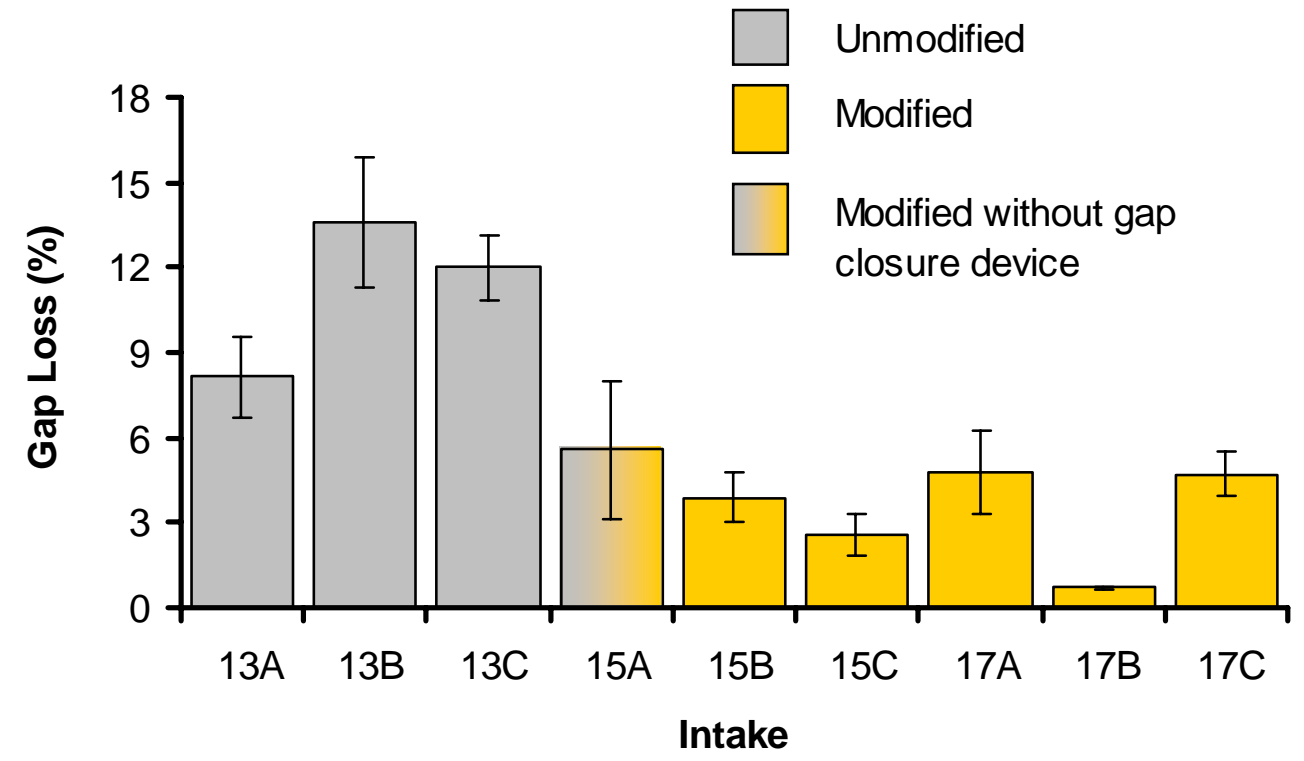

Figure 3.5. Gap loss as a percent of gatewell and gap-loss passage at nine intakes sampled three nights each in spring 2003. Vertical bars are 95\% confidence intervals about the mean. 
A plot of mean gap loss ( $\mathrm{N}=3$ nights) by intake sampled in summer 2003 suggests that two of the unmodified intakes at Unit 13 had higher losses than all other intakes and that most other estimates, except perhaps that of 17C, which was very low, probably did not differ significantly (Figure 3.6).

\section{DIDSON-based Estimates in Summer}

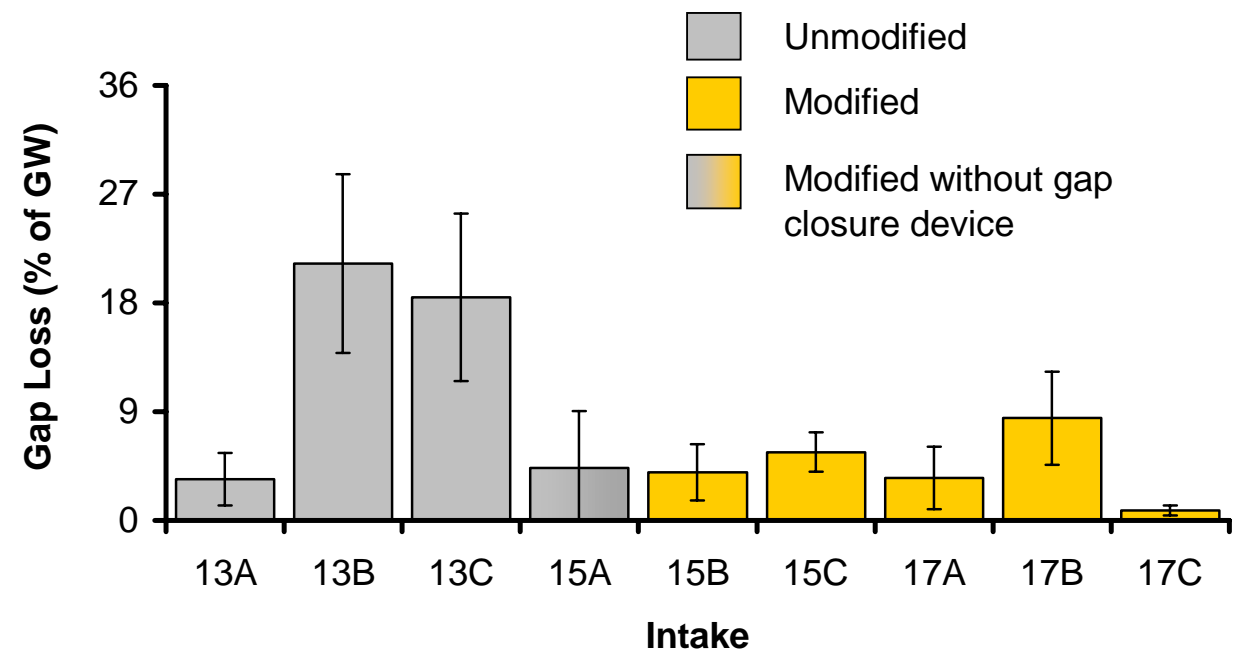

Figure 3.6. Gap loss as a percent of gatewell and gap-loss passage at nine intakes sampled three nights each in summer 2003. Vertical bars are 95\% confidence intervals about the mean.

A plot of mean gap loss ( $\mathrm{N}=9$ nights $)$ by turbine unit sampled in spring 2003 indicated that Unit 13 with an unmodified gatewell slot had significantly higher gap loss estimates than did Units 15 and 17, which had modified gatewell slots (Figure 3.7; Table 3.2). Similarly, a plot of mean gap loss ( $\mathrm{N}=9$ nights) by unit sampled in summer 2003 showed that Unit 13 with an unmodified gatewell slot had significantly higher gap loss than Units 15 and 17, with modified gatewell slots (Figure 3.8; Table 3.2).

\section{DIDSON-based Estimates in Spring}

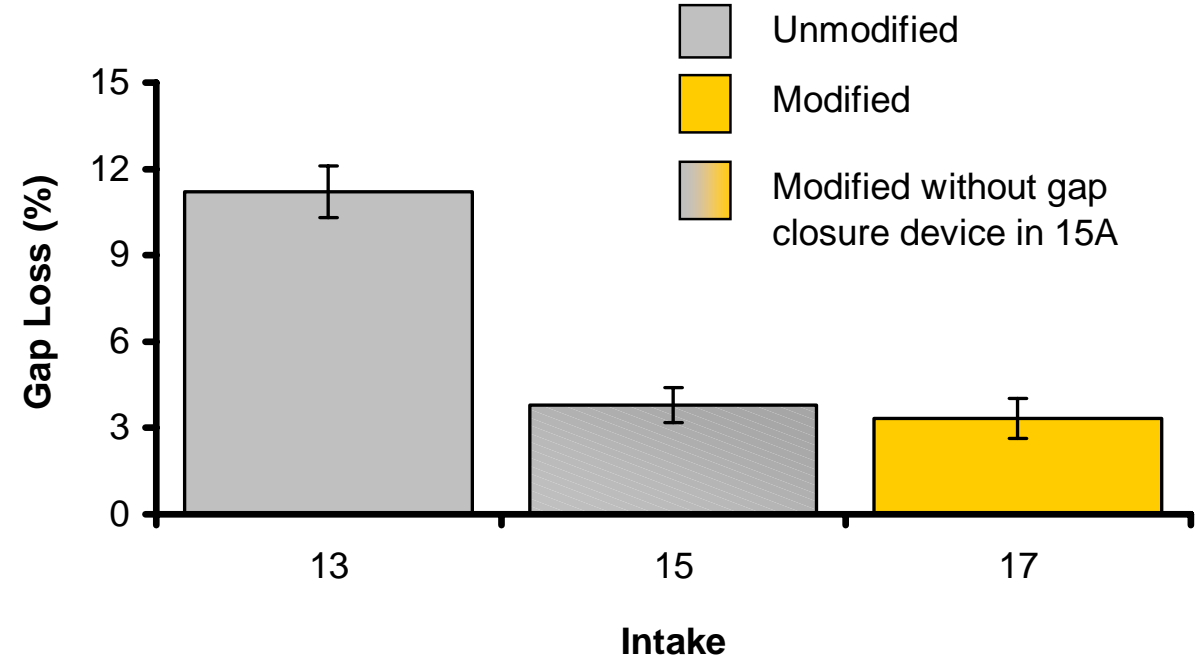

Figure 3.7. Gap loss as a percent of gatewell and gap-loss passage at three turbine units sampled nine nights each in spring 2003. Vertical bars are 95\% confidence intervals about the mean. 


\section{DIDSON-based Estimates in Summer}

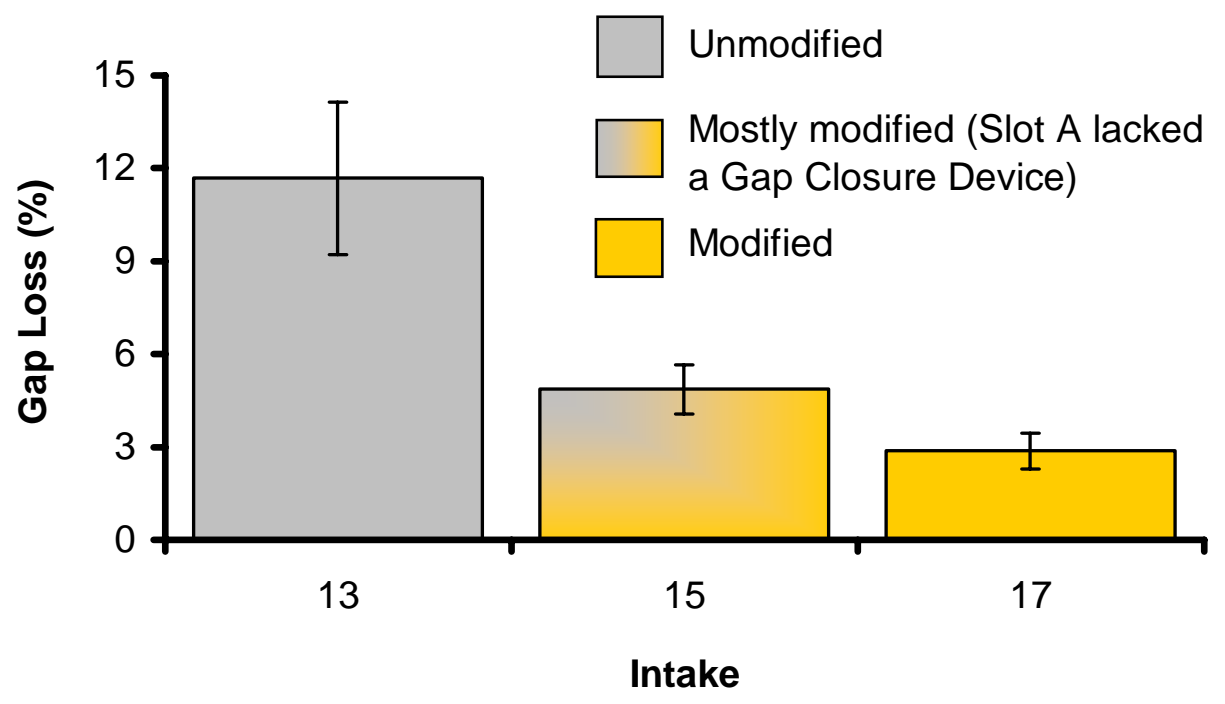

Figure 3.8. Gap loss as a percent of gatewell and gap-loss passage at three turbine units sampled nine nights each in summer 2003. Vertical bars are 95\% confidence intervals about the mean. $\mathrm{GCD}=$ Gap Closure Device

Given the patterns observed in DIDSON-based estimates of gap loss among units with modified and unmodified gatewell slots, we also graphed gap-loss estimates as a percent of gatewell and gap passage based upon netting data collected by NOAA Fisheries (Figure 3.9). The netting estimates of gap loss were about one-third of the DIDSON-based estimates, but the pattern of reduced gap-loss at modified intakes relative to unmodified intakes is similar. Both sets of data indicate that modified units have gap losses that are about $30 \%$ of those observed at unmodified units.

\section{Netting Data (NOAA Fisheries)}

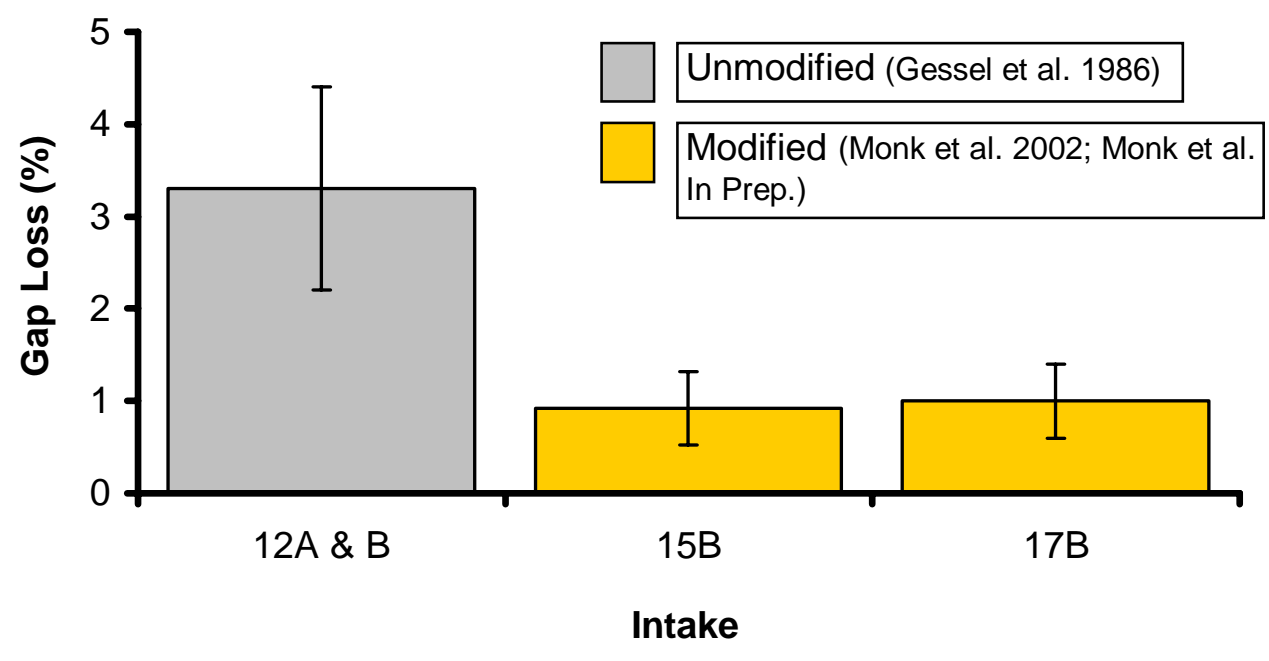

Figure 3.9. Gap loss as a percent of gatewell and gap-loss passage at turbine intakes with modified and unmodified gatewell slots as determined by netting in 1985, 2001, and 2002 by NOAA Fisheries. Vertical bars are $95 \%$ confidence intervals about the mean. 
Table 3.2. Tables of Analysis of Variance and Least Square Mean Comparisons of Differences in Mean Gap Loss among Sampled Units at Powerhouse 2 in Spring and Summer

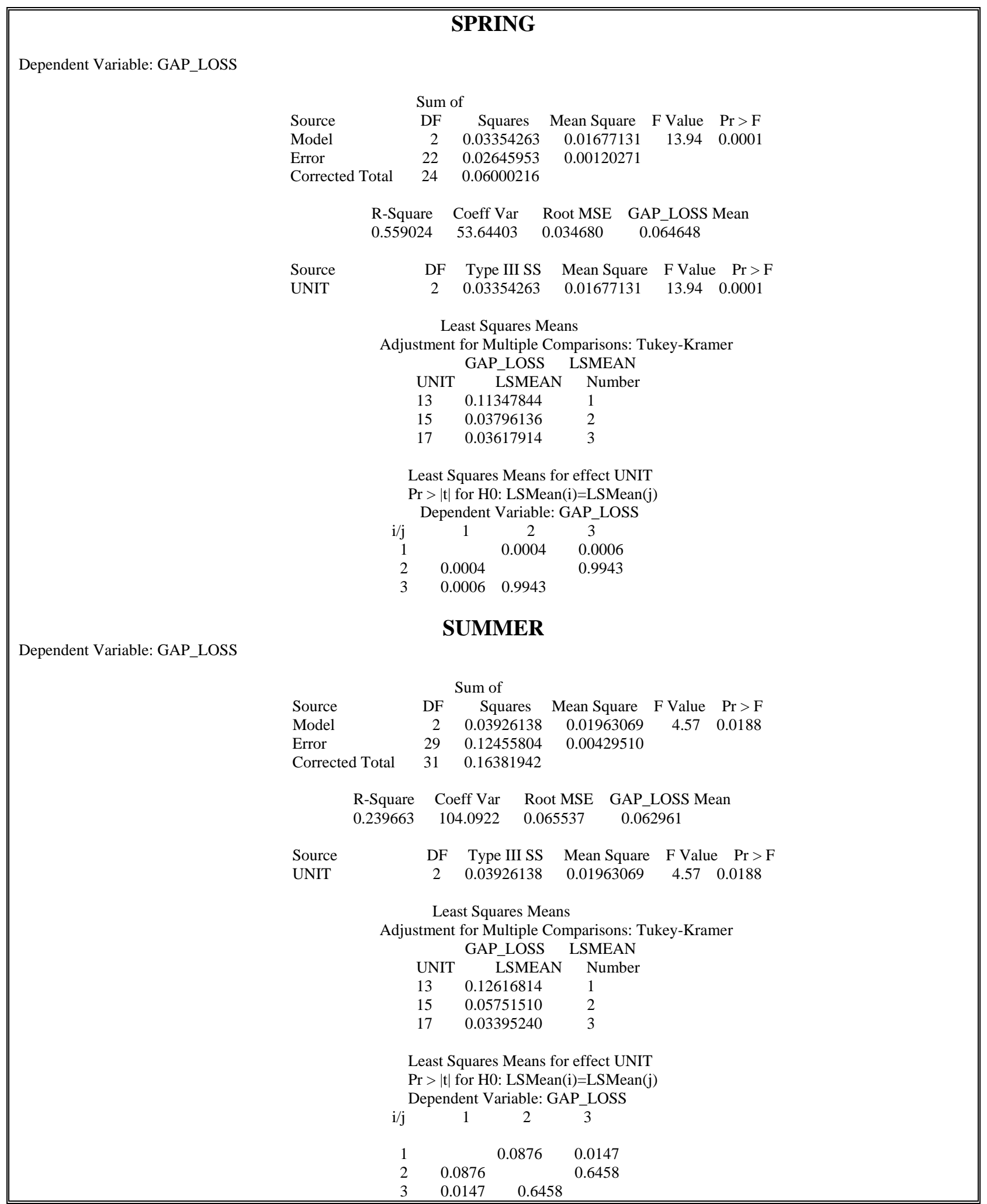


Given the uncertainties in discriminating between fish and non-fish in DIDSON images during summer, we limited our examination of diel and horizontal distribution to data acquired in spring 2003. The diel distribution of fish passage into the gatewell slot at Intake 13B peaked at about sunset (20002200 hours). Except for the peak at sunset, gatewell passage was consistently higher during the day than it was at night (Figure 3.10). Gap passage tended to be higher from 0600 through 2200 than it was from 2200-0600 hours, and there were two distinct peaks, one at 0800-1000 hours and another from 2000-2200 hours. Gap loss as a percent of gatewell and gap passage averaged 9.9\% with no strong diel pattern, except that it was higher from 0600 to 1000 hours (Figure 3.11) than at other times.

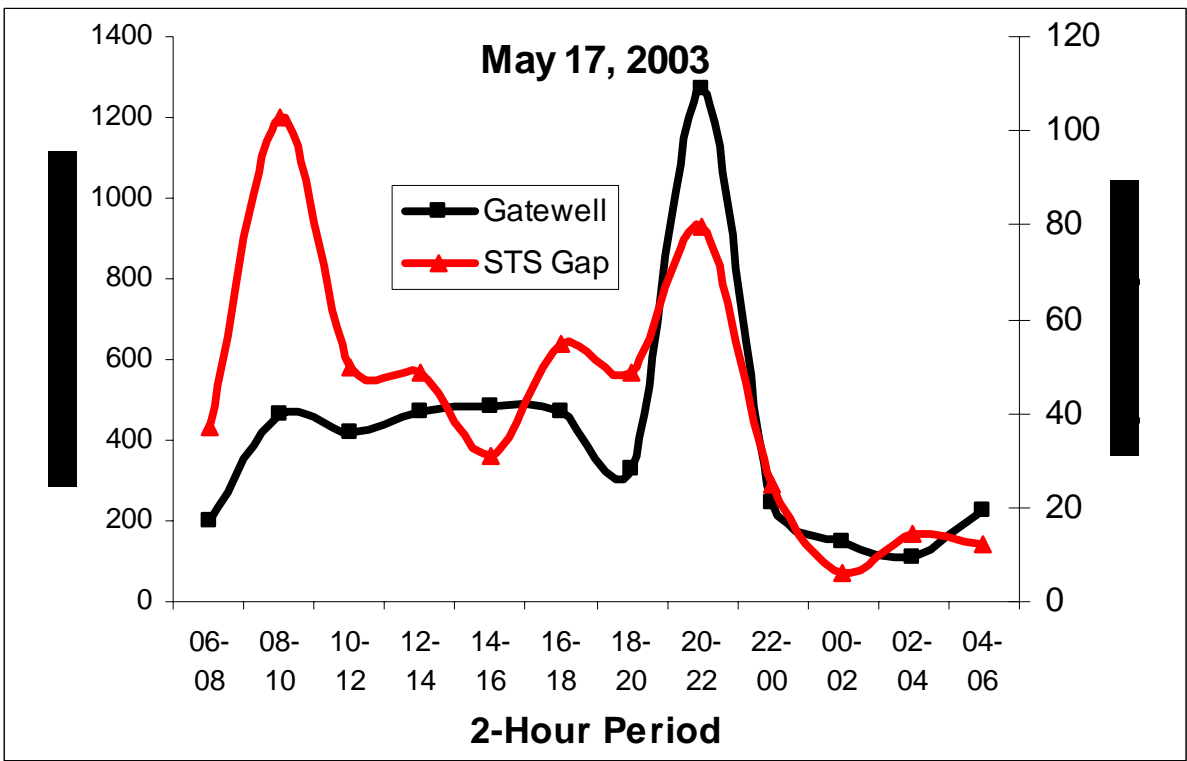

Figure 3.10. Plot of the diel trend of fish passage into the gatewell and gap on May 17, 2003.

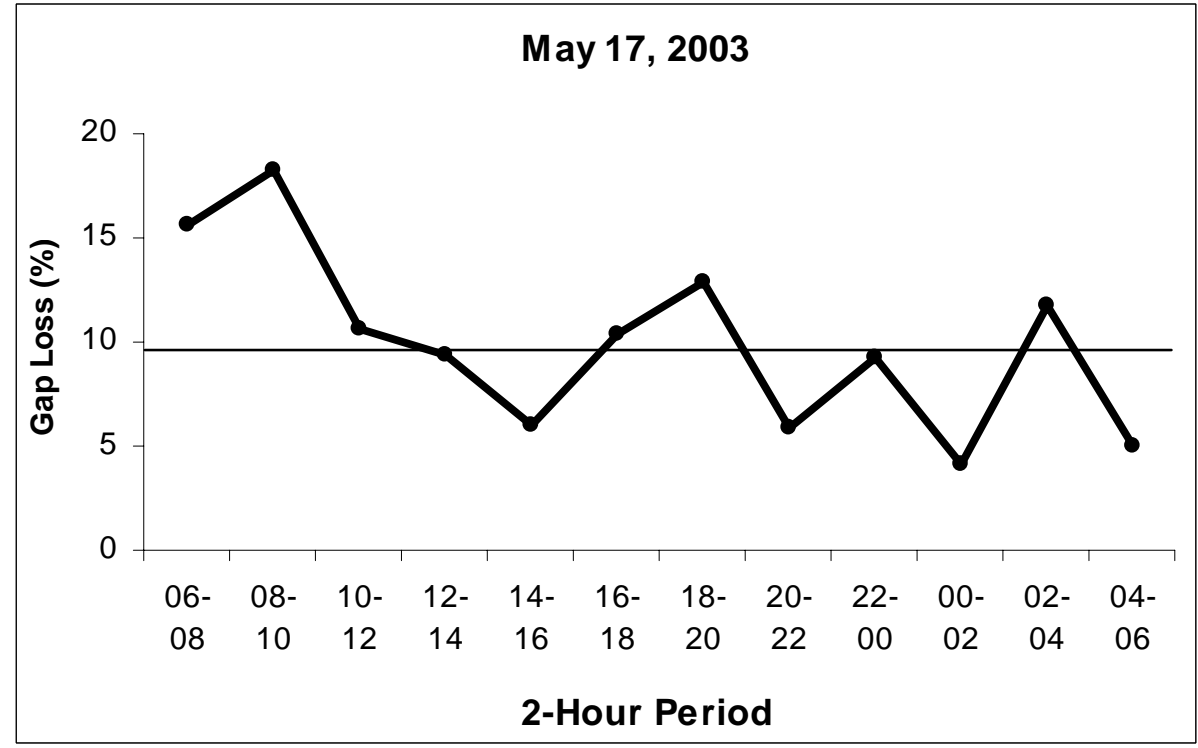

Figure 3.11. Plot of the diel trend in gap loss as a percent of gatewell and gap-loss passage at Intake 13B on May 17, 2003. The horizontal line is the average loss. 
The horizontal distribution of gap loss as a percent of gatewell and gap passage was not uniform at any of the units sampled, and the patterns varied among units (Figure 3.12).

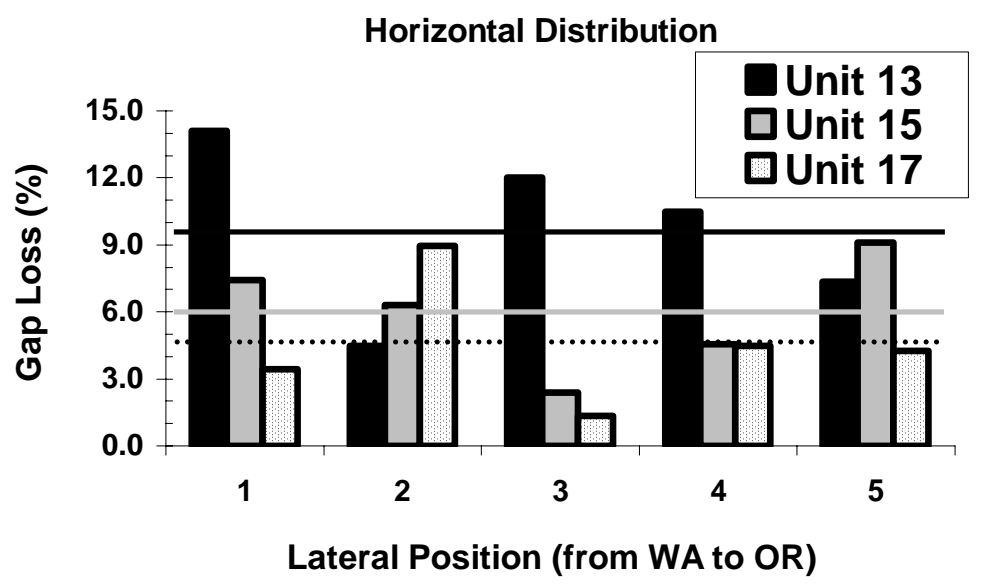

Figure 3.12. Bar chart of the horizontal distribution of gap loss as a percent of gatewell and gap passage among five equidistant position across the width of the gatewell slot at unmodified Unit 13 and modified Units 15 and 17 in 2003 . The horizontal lines represent the mean gap loss for each unit.

During summer sampling at Intake $17 \mathrm{C}$, turbine 17 was operated at low and high discharge levels associated with the lower and upper end of the $1 \%$ operating efficiency range to see whether discharge affected gap loss. There were three nights of low-discharge operations and four nights of high-discharge, but we found no significant difference in gap loss as a fraction of gatewell and gap passage (Table 3.3). Intake $17 \mathrm{C}$ had the lowest gap loss of any intake sampled in summer and variability among days was low (Figure 3.6).

Table 3.3. Analysis of variance table for comparing mean gap loss at Intake $17 \mathrm{C}$ in summer during three nights of low discharge and four nights of high discharge.

\section{Dependent Variable: GAP_LOSS}

\begin{tabular}{lrrrrrr} 
& \multicolumn{2}{l}{ Sum of } & & & \\
Source & DF & Squares & Mean Square & F Value & Pr $>$ F \\
Model & 1 & 0.00013546 & 0.00013546 & 0.42 & 0.5454 \\
Error & 5 & 0.00161169 & 0.00032234 & & \\
Corrected Total & & 6 & 0.00174715
\end{tabular}

R-Square Coeff Var Root MSE GAP_LOSS Mean

$\begin{array}{llll}0.077534 & 192.4182 & 0.017954 & 0.009331\end{array}$

Source DF Type III SS Mean Square F Value $\operatorname{Pr}>\mathrm{F}$

$\begin{array}{llllll}\text { Discharge Condition } & 1 & 0.00013546 & 0.00013546 & 0.42 & 0.5454\end{array}$ 
The length frequency distribution of fish passing through the gap and up into the gatewell slots in spring were generally similar except that the gap claimed a higher percentage of fish in the 100- and 125$\mathrm{mm}$ length classes and a lower percentage of fish in the 150-, 175-, and 200-mm length classes (Figure 3.13).
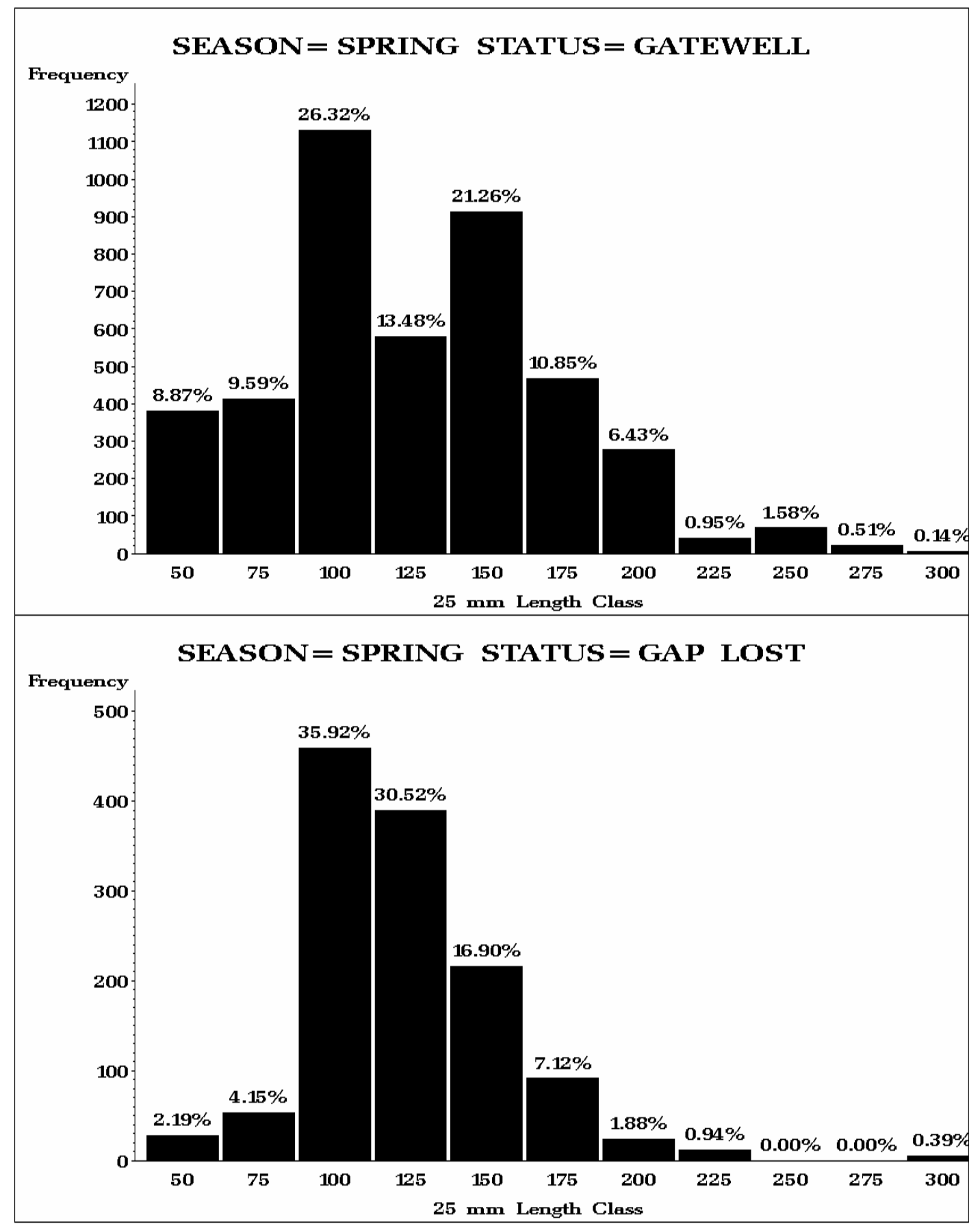

Figure 3.13. Length frequencies based on the number fish passing up into the gatewell slots (upper chart) and through the gap between the top of the STS and the intake ceiling (lower chart) in spring 2003 based upon DIDSON data. 
The length frequency distribution of fish passing through the gap and up into the gatewell slots in spring were very different, with the gatewell fraction skewed toward smaller fish and the gap loss fraction skewed toward larger fish (Figure 3.14). Most sub-yearling fish were about $100 \mathrm{~mm}$ long according to data from the smolt-monitoring facility, but both length frequency distributions contained large percentages of fish in the 50- and 75-mm length classes.

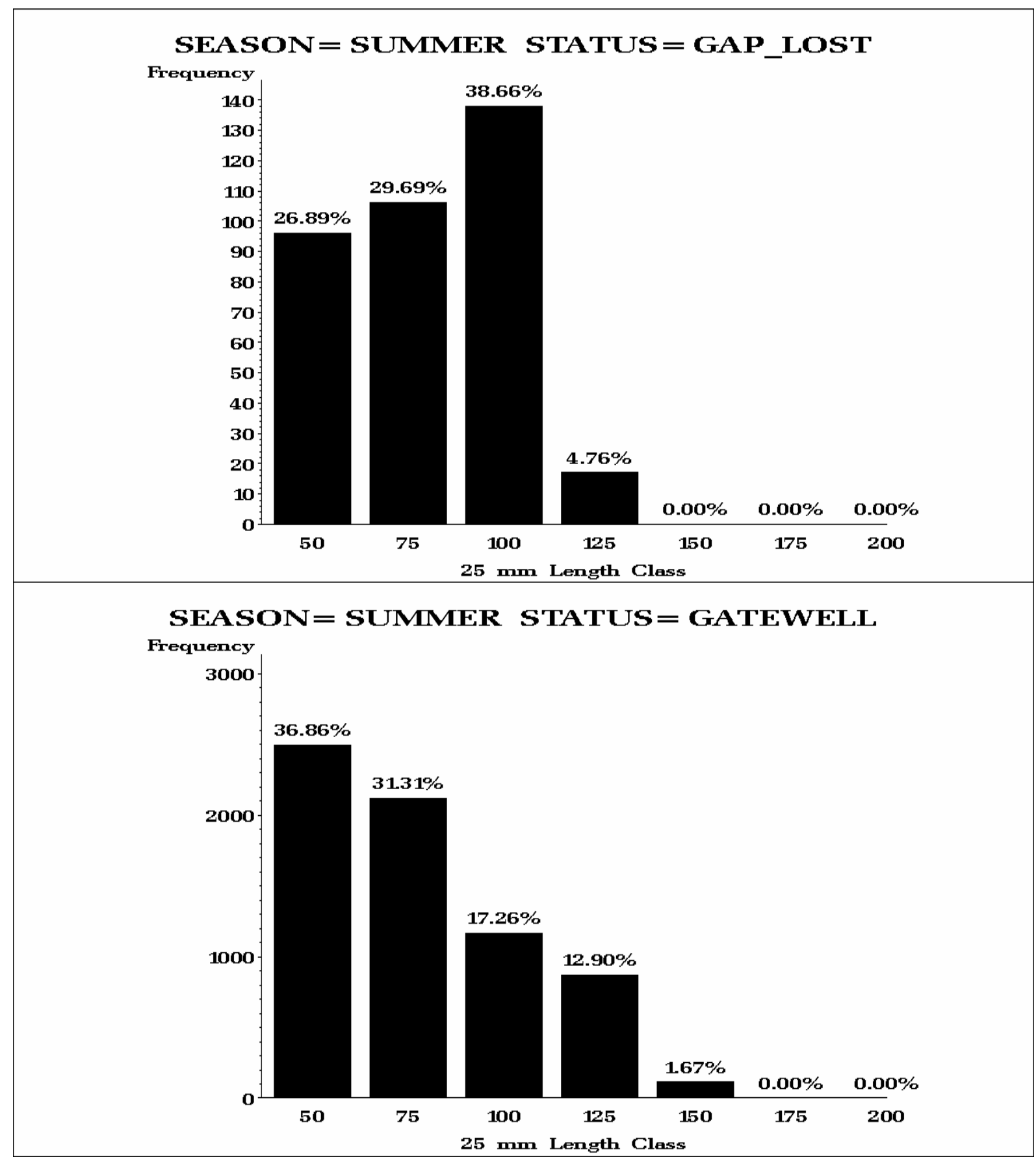

Figure 3.14. Length frequencies of fish passing up into the gatewell slots (upper chart) and through the gap between the top of the STS and the intake ceiling (lower chart) in summer 2003 based upon DIDSON data. 
Evaluation of Fish Losses through Screen Gaps at Bonneville Second Powerhouse in 2003 


\subsection{Discussion}

\subsection{Operation Effects}

Our high- and low-discharge test in summer to determine whether gap loss was affected by operations did not detect a significant difference in gap loss, but discharge conditions on "low" and "high" discharge days were similar. The mean daily discharge ranged from 12,811 to $13,922 \mathrm{ft}^{3} / \mathrm{s}$ on the four lowdischarge days (mean $=13,385 \mathrm{ft}^{3} / \mathrm{s}$ ) and from 13,113 to $13,623 \mathrm{ft}^{3} / \mathrm{s}\left(\right.$ mean $\left.=13,341 \mathrm{ft}^{3} / \mathrm{s}\right)$ on the three high-discharge days. Even when operating at the lower end of the $1 \%$ efficiency curve at a single unit, other less controllable factors such as forebay and tailwater elevations (i.e., head) have a significant impact upon turbine discharge. The daily range in forebay elevation was about $3 \mathrm{ft}$ (Figure 3.2). Also, estimates of gap loss at Intake 17C happened to be among the lowest and least variable detected during the study, so it is very likely that the test lacked adequate statistical power to detect small differences in gap loss proportion if any existed.

Diel estimates of gap loss were not correlated with diel changes in forebay elevation, and this suggests either that our debris filters were reasonably effective in discriminating between fish and debris, or debris loading was not related to changes in pool, or both. Only about $1.5 \%$ of gap-loss percentages were explained by 2 -h changes in pool elevation, and the slope of the correlation line between percent gap loss and change in pool elevation did not differ significantly from zero. During 24-h sampling on May 17, 2003, pool elevations mostly increased from about $2100 \mathrm{~h}$ through dawn (Figure 3.3), while gap-loss counts were the lowest of the 24-h period (Figure 3.10). Gap loss, as a percent of gatewell and gap passage was highest from 0600 through $1000 \mathrm{~h}$ (Figure 3.11), a time when pool elevations were increasing, but percent gap loss declined over the next four hours, even though pool elevation continued to increase.

\subsection{Optical Camera Sampling at Unmodified Unit 13}

Optical cameras deployed in the gatewell slots had very limited fields of view (maximum range less than 10 inches) for detecting objects passing through the STS gaps, and therefore the best we could do was describe proportions of detected objects that could have been fish. The reason for limited visibility for the optical cameras is not clear, but there was a lot of backscatter of infrared light from particulate materials in the water, and it may be that the infrared light did not completely illuminate the entire field of view of the optical cameras. Because of its longer wavelength, infrared light does not travel as far in water as does visible light. We were able to see infrared light from opposing cameras about $8 \mathrm{ft}$ away in the center of the fields of view, so infrared light penetration of the water did not seem to be a problem. The optical cameras clearly revealed that most detected objects were not fish, and this information led us to evaluate what the DIDSON camera was capable of imaging. After determining that the acoustic camera imaged non-fish objects like waterlogged sticks, pieces of macrophytes, and other debris just as well as it did fish, it was obvious that preliminary unfiltered estimates of gap loss from the acoustic camera were too high. Rotation of the STS fabric carries a lot of debris to the top of the screens, and most of those items pass through the STS gap, which makes the use of the DIDSON problematic for counting fish passing through the gap unless images are carefully characterized and filtered to exclude debris. 


\subsection{DIDSON-Based Estimates}

We were reassured when filtered estimates and adjusted estimates obtained by multiplying unfiltered estimates by fish fractions (possible fish/possible fish + non-fish) detected with optical cameras were within $6 \%$ of each other (Table 3.1). More stringent filters of acoustic camera detections produced lower estimates of gap loss than those obtained from unfiltered DIDSON counts and fish fractions in optical camera detections, so we believe that the final filters for DIDSON counts were reasonable.

Although the true magnitude of STS gap-loss is unknown, our results suggest that that gatewell modifications reduce relative gap loss by about 67\% (see Figures 3.7 through 3.9), which is in general agreement with NMFS netting results (Figure 3.9). The similarity in gap-loss patterns between modified and unmodified units sampled by the DIDSON and by netting is reassuring. Gap netting estimates were about $25 \%$ to $33 \%$ of DIDSON-based estimates, ranging from about $1 \%$ of the combined gatewell and gap-net catch for modified units to about $3.25 \%$ of the combined catch for unmodified units. DIDSONbased estimates were $3.0 \%$ to $3.5 \%$ of gatewell and gap detections for modified Units 15 and 17 in spring and $3.0 \%$ to $4.5 \%$ for modified units in summer, but these estimates were lower than those for unmodified Unit 13 (11.0\% in spring and $11.5 \%$ in summer). If the filters used to discriminate between debris and fish in DIDSON images were less than $100 \%$ effective, which is likely, our estimates could be inflated.

On the other hand, some fish undoubtedly move through the gap head first or roll off of the top of the STS and are detected in fewer than the four-frame minimum. Those losses would produce underestimates that could at least partially compensate for inflation by counting debris. Netting estimates of gap loss also likely have some bias, because clogging of the gap net over time would reduce the efficiency of the gap net by forcing a greater proportion of the flow up the gatewell slot. Gap-net efficiency would decrease more rapidly with higher debris loading until it shunts most of the flow and fish up into the gatewell slot. Williams et al. (1996) concluded that FGE estimates by fyke netting were biased upward by a pressure field created by the fyke nets located under the STSs at McNary Dam. An analogous phenomenon could be occurring with the gap net, especially when it clogs with debris during FGE sampling.

The true magnitude of gap loss is of less importance for evaluating effects of gatewell modification on gap loss than it is for assessing effects on hydroacoustic and netting estimates of FGE. If gap losses of unmodified units average $10 \%$ to $12 \%$ of total gatewell and gap passage), as suggested by the estimates developed in this study, then FGE estimates by traditional hydroacoustics [guided - gap loss / (guided + gap loss + unguided)] are overestimated by about 5\% to $6 \%$ when FGE is $50 \%$. Hydroacoustic estimates of guided passage are made from counts before fish reach the gatewell and include the entire unknown fraction that may be lost to the gap. Netting estimates of guided fish could be high if nets shunt some proportion of gap-lost fish into the gatewell fraction, thereby increasing the guided fraction and underestimating gap loss. We recommend additional attempts to quantify gap losses, in addition to assessing the relative effects of gatewell modifications, so that the implications for hydroacoustic and netting estimates of FGE can be better understood.

Losses of fish through the gap between the tops of the STSs and the bottoms of the intake ceilings may explain some of the difference between FGE estimates by hydroacoustics, netting, and radio telemetry, provided that some gap-lost fish are detected by radio-telemetry antennas mounted on the downstream side of the STSs. If gap losses are included in FGE estimates by radio telemetry, partially included in netting estimates, and not included in hydroacoustic estimates, managers can view 
hydroacoustic and netting estimates as the potential FGE that could be achieved and radio-telemetry estimates as the worst case including gap loss. In spring 2002, Ploskey et al. (2003) found better correlation between hydroacoustic and radio telemetry estimates of the percent distribution of fish passage among B2 units than they did between FGE estimates for specific units. Both methods detected a southerly skew in the distribution of fish passage. The estimated percentage of fish that passed through the south half of B2 was $64 \%$ by hydroacoustic sampling and 73\% by radio telemetry. Units 11 and 12 accounted for $40 \%$ (radio telemetry) to $45 \%$ (hydroacoustics) of all fish passing at B2. The FGE estimates by both methods were within $5 \%$ and $8 \%$ of each other at Units 11 and 12, respectively, where fish-passage numbers were highest. The greatest deviations in estimates by the two methods occurred at the north end of the powerhouse. At Unit 17, there was a 39\% difference in estimates (FGE $=66 \%$ by hydroacoustics and $27 \%$ by telemetry). The netting estimate by NOAA fisheries (Monk et al., In prep.) averaged $60 \%$, about $5 \%$ below the hydroacoustic estimate (Ploskey et al 2003) and 33\% above the radio telemetry estimate (Evans et al. 2003).

The peak in gatewell and gap passage that we saw around sunset (2000-2200 hours) in spring is consistent with the general trend in turbine passage at Bonneville Dam (e.g., Ploskey et al. 2003). These evening peaks reassured us that our debris filters were working because we would expect no evening peak in the diel pattern in gap loss if counts were dominated by non-fish detections. The high gap loss as a percentage of gatewell and gap passage from 0600 to 1000 hours (Figure 3.11) resulted from moderate to high gap passage at a time when gatewell passage was not high, which is suspicious. Except for the twohour period from 0800 to 1000 hours, trends in gatewell and gap passage were similar (Figure 3.10), so it may be that the gap-loss fraction was dominated by debris from 0800 to 1000 hours, a time period for which we did no video analysis. Gatewell passage explained just $43 \%$ of gap passage for all 2-h periods sampled during the diel cycle, but $70 \%$ of gap passage when the $0800-1000$-h period was excluded (Figure 4.1). Estimates of gatewell passage probably are a more reliable indicator of diel timing of fish passage than are estimates of gap passage because all objects in the gatewell are detected in many frames and are easier to characterize and filter than are gap-lost objects.

The horizontal distribution of fish passage into the gatewell and gap was not uniform within or among units, which indicates that moving the DIDSON (or any other sampling device) laterally is important to minimize bias. Increased sophistication of processing methods to provide detailed characterization of images and improve discrimination of fish from debris limited the number of hours of data that could be reasonably processed from each night's sample. Our goal of basing nightly gap loss percent on at least 100 detections in the gatewell and gap allowed us to obtain estimates within study resources but prevented us from processing data from more than three or four of the five horizontal positions within the intake that we sampled each night. As a result, gap-loss estimates for individual intakes include some unknown bias because one or two of the five positions were not processed each night. At least the data that were processed came from the portion of the night when staff was moving the acoustic camera every 30 minutes. Any future effort should process samples from all five lateral positions every night, either by increasing processing effort or by shortening the sampling time at each location from 30 to 10 or 20 minutes. Autotracker development for processing acoustic camera images from gatewell slots is unlikely to be successful because of the confined and noisy environment. Our attempts to develop an autotracker for DIDSON data from gatewell slots were unsuccessful, although development for deployments in more open and less noisy environments, such as a forebay, is promising. 


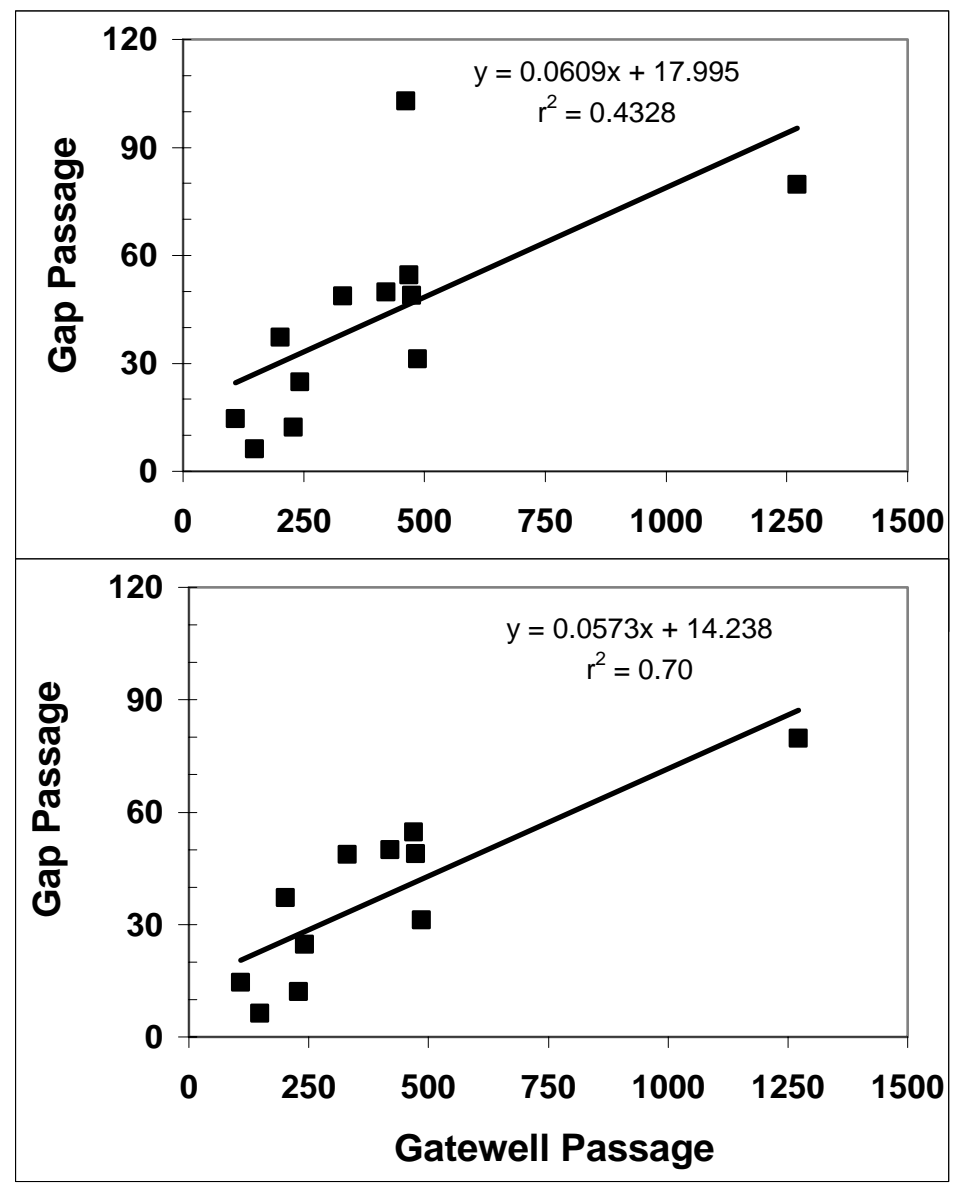

Figure 4.1. Plots of 2-hour rates of gap passage as a percent of gatewell and gap-loss passage at Intake 13B on May 17, 2003. The upper plot includes the point for 0800-1000 hours, whereas the bottom plot omits the 0800-1000 hour point.

The length-frequency distributions of fish detected in the gatewell and STS gap were reasonable in spring (Figure 3.13) but not in summer (Figure 3.14), and differences in distributions of gatewell and gaplost fish in summer likely resulted from differences in fish orientation upon detection. We could not discriminate reliably between small summer fish and bubbles in the gatewell fraction in summer. Not only were the summer fish smaller on average, but they usually were oriented upward as they entered the gatewell slot and presented head-aspect images that appeared smaller than would images from similarsized fish oriented horizontally as they pass through the gap. The length-frequency distribution of fish detected in the gaps in summer was not as unreasonable as was that of summer fish detected in the gatewell slots (see Figure 3.14). We would expect sub-yearling smolts in summer to range from 50 to about $125 \mathrm{~mm}$ in length with the mean and mode around $100 \mathrm{~mm}$. The length-frequency of targets classified as fish in the gatewell in summer was clearly biased toward 50 and $75 \mathrm{~mm}$ length class fish, and this likely reflects our inability to properly measure small fish in head aspect.

Given problems in resolving and discriminating between sub-yearling fish and non-fish objects in summer, we recommend limiting gap-loss studies with the acoustic camera to spring. We also cannot rule out that detection problems in summer resulted from differences in spring and summer deployments, because many sub-yearling chinook are released from hatcheries and pass Bonneville Dam in spring as 
well as summer. Many of the fish smaller than the 100-mm length class in Figure 13.13 likely were subyearling fish, but none of the people processing DIDSON data recalled having detection problems in spring like those encountered in summer. The DIDSON was deployed the same distance above the STS in summer as it was in spring, but the sampling window in summer was shortened from 4 to $2 \mathrm{~m}$ to increase resolution, and this may have been responsible for poor length-frequency data on gatewelldetected fish in summer. If future studies are conducted, this hypothesis should be tested so that potentially inferior sampling methods are avoided.

In this study we have learned a good deal about the limitations of the DIDSON for sampling locations where entrained debris is common. Because of the DIDSON's capability of imaging non-fish objects it is likely that the 2002 DIDSON-based estimates of gap loss were too high. That study determined that we could deploy, maintain, and move the instrument in the very challenging gatewell environment and produce useable gap-loss data with it. In the course of this study we have developed ways to discriminate between fish and non-fish objects in the STS gap, but it was beyond the scope of this project to reanalyze the 2002 DIDSON data.

Discrimination between fish and non-fish targets would be much easier for deployments in less noisy environments such as forebay areas upstream of sluiceway entrances, turbine trash racks, or spill bays, or when the number of frames in which a target is visible exceeds six and frame-to-frame undulation in fish is obvious. Side-looking deployments with the fan of 96 beams arrayed horizontally would be best for detecting frame-to-frame undulation. The acoustic camera may not be the ideal method for quantifying gap loss, but it appears to be adequate to detect relative differences in gap loss between modified and unmodified units based upon nine samples per unit (three in each intake), at least in springtime. Three samples per intake are minimal for consistently detecting significant differences among modified and unmodified intakes.

Our primary finding, that the recent gatewell modifications at B2, which were undertaken to improve fish guidance by the screens, have also substantially reduced gap loss, is encouraging for future improvement in the District's efforts to reduce turbine passage and increase project survival for juvenile salmonids in the future. 
Evaluation of Fish Losses through Screen Gaps at Bonneville Second Powerhouse in 2003 


\subsection{Conclusions and Recommendations}

\subsection{Conclusions}

Gatewell and gap sampling with an acoustic camera is possible, but there is an important need to distinguish fish from non-fish debris using filters and a very serious problem separating small summer migrants from debris and air-bubbles.

Gatewell modifications reduced gap loss rates in the intakes of Units 15 and 17 by about $67 \%$ compared with the rate at unmodified intakes of Unit 13. Our results are similar to results from previous NMFS netting studies.

\subsection{Recommendations}

Given problems in resolving and discriminating between sub-yearling fish and non-fish objects in summer, we recommend limiting gap-loss studies with the DIDSON to spring.

We recommend additional studies to quantify gap losses and understand sampling biases so that the implications for hydroacoustic and netting estimates of FGE can be better understood. A study combining DIDSON and gap-net sampling may be warranted.

We recommend studies to determine the relative contribution of the turning vane and gap-closure devices to the gap-loss reductions. Complete modifications to turbine intakes to improve FGE are expensive, but some benefit in terms of increased FGE and reduced gap loss may be realized by less expensive partial modifications. 
Evaluation of Fish Losses through Screen Gaps at Bonneville Second Powerhouse in 2003 


\subsection{References}

Belcher, E.O., H.Q. Dinh, D.C. Lynn, TJ Laughlin. 1999. Beam forming and imaging with acoustic lenses in small, high-frequency sonars. Proceeding of Oceans '99 Conference, 13-16 September.

Evans, S. D., L. S. Wright, C. D. Smith, R. E. Wardell, N. S. Adams, and D. W. Rondorf. 2003. Passage Behavior of Radio-Tagged Yearling Chinook Salmon and Steelhead at Bonneville Dam, 2002. Annual Report by the U.S. Geological Survey Columbia River Research Laboratory for the U.S. Army Corps of Engineers Portland District, Portland, OR, USA.

Gessel, M. H. L. G. Gilbreath, W. D. Muir, and R. F. Krcma. 1986. Evaluation of the juvenile collection and bypass system at Bonneville Dam - 1985. Report to U.S. Army Corps of Engineers, Contract DACW57-85-H-0001, 64 p. plus Appendix. (Available from Northwest Fisheries Science Center, 2725 Montlake Blvd. E., Seattle, WA 98112-2097.)

Gessel, M. H., J. G. Williams, D. A. Brege, R. F. Krcma, and D. R. Chambers. 1991. Juvenile salmonid guidance at Bonneville Dam Second Powerhouse, Columbia River, 1983-1989. N. Am. J. Fish. Manage. 11:400-412.

Krcma, R.F., M. H. Gessel, W. D. Muir, C. S. McCutcheon, L. G. Gilbreath, and B. H. Monk. 1984. Evaluation of the juvenile collection and bypass system at Bonneville Dam - 1983. Report to U.S. Army Corps of Engineers, Contract DACW57-83-F-0315, 56 p. plus Appendix. (Available from Northwest Fisheries Science Center, 2725 Montlake Blvd. E., Seattle, WA 98112-2097.)

Monk, B. H., B. P. Sandford, and D. B. Dey. 1994. Evaluation of the fish guidance efficiency of submersible traveling screens and other modifications at Bonneville Dam second Powerhouse, 1993. Report to U.S. Army Corps of Engineers, Delivery Order E96930031, 26 p. plus Appendix. (Available from Northwest Fisheries Science Center, 2725 Montlake Blvd. E., Seattle, WA. 981122097).

Monk, B. H., B.P. Sandford, and D.B. Dey. 1995. Evaluation of the fish guidance efficiency of submersible traveling screens and other modifications at Bonneville Dam second Powerhouse, 1994. Report to U.S. Army Corps of Engineers, Delivery Order E96940027, 15 p. plus Appendix. (Available from Northwest Fisheries Science Center, 2725 Montlake Blvd. E., Seattle, WA. 981122097).

Monk, B. H., R. F. Absolon, B. P. Sandford, and J. W. Ferguson. 2002. Evaluation of intake modifications at Bonneville Dam Second Powerhouse, 2001. Report of Research by the Fish Ecology Division, N. W. Fisheries Science Center, NOAA Fisheries for the U. S. Army Engineer District, Portland, OR.

Monk, B., J. W. Ferguson, and B. Sandford. In Preparation. Evaluation of intake modifications at Bonneville Dam Second Powerhouse, 2002. Draft Report to U.S. Army Corps of Engineers. Available from Northwest Fisheries Science Center, 2725 Montlake Blvd. E., Seattle, WA. 981122097. 
National Marine Fisheries Service. 2000. Endangered Species Act -Section 7 Consultation conducted by National Marine Fisheries Service. Biological Opinion - Reinitiation of Consultation on Operation of the Federal Columbia River Power System, Including the Juvenile Fish Transportation Program, and 19 Bureau of Reclamation Projects in the Columbia Basin. Date issued December 21, 2000.

Ploskey, G. R., C. R. Schilt, J. Kim, C.W. Escher, and J. R. Skalski. 2003. Hydroacoustic Evaluation of Fish Passage through Bonneville Dam in 2002. Technical Report by the Pacific Northwest National Laboratory, Richland, WA for the U. S. Army Engineer District, Portland, OR.

Ploskey, G. R., C. R. Schilt, M. E. Hanks, J. R. Skalski, W. T. Nagy, P. N. Johnson, D. S. Patterson, J. Kim, L. R. Lawrence. 2002. Hydroacoustic Evaluation of Fish Passage Efficiency Through Bonneville Dam in 2000. ERDC/EL TR-02-8, U. S. Army Engineer Research and Development Center, Vicksburg, MS.

Ploskey, G. R., L. R. Lawrence, P. N. Johnson, W. T. Nagy, and M. G. Burczynski. 1998. Hydroacoustic evaluations of juvenile salmonid passage at Bonneville Dam including surface-collection simulations. Technical Report EL-98-4, U. S. Army Engineer Waterways Experiment Station, Vicksburg, MS.

Ploskey, G. R., W. T. Nagy, L. R. Lawrence, D. S. Patterson, C. R. Schilt, P. N. Johnson, and J. R. Skalski. 2001. Hydroacoustic evaluation of juvenile salmonid passage through experimental routes at Bonneville Dam in 1998. ERDC/EL TR-01-2, U. S. Army Engineer Research and Development Center, Vicksburg, MS.

Williams, J. G., M. H. Gessel, B. P. Sandford, and J. J. Vella. 1996. Evaluation of factors affecting juvenile chinook salmon fish guidance efficiency. Report to U.S. Army Corps of Engineers, Walla Walla District, Contract E86910059, 35 p. (Available from Northwest Fisheries Science Center, 2725 Montlake Blvd. E., Seattle, WA 98112-2097.) 


\title{
DISCLAIMER
}

This report was prepared as an account of work sponsored by an agency of the United States Government. Neither the United States Government nor any agency thereof, nor Battelle Memorial Institute, nor any of their employees, makes any warranty, express or implied, or assumes any legal liability or responsibility for the accuracy, completeness, or usefulness of any information, apparatus, product, or process disclosed, or represents that its use would not infringe privately owned rights. Reference herein to any specific commercial product, process, or service by trade name, trademark, manufacturer, or otherwise does not necessarily constitute or imply its endorsement, recommendation, or favoring by the United States Government or any agency thereof, or Battelle Memorial Institute. The views and opinions of authors expressed herein do not necessarily state or reflect those of the United States Government or any agency thereof.

\author{
PACIFIC NORTHWEST NATIONAL LABORATORY \\ operated by \\ BATTELLE \\ for the
}

\section{UNITED STATES DEPARTMENT OF ENERGY}

under Contract: DE-AC06-76RLO1830

Printed in the United States of America
Available to DOE and DOE contractors from the Office of Scientific and Technical Information, P.O. Box 62, Oak Ridge, TN 37831-0062;
ph: (865) 576-8401
fax: (865) 576-5728
email: reports@adonis.osti.gov

Available to the public from the National Technical Information Service, U.S. Department of Commerce, 5285 Port Royal Rd., Springfield, VA 22161

ph: (800) 553-6847

fax: (703) 605-6900

email: orders@ntis.fedworld.gov

online ordering: http://www.ntis.gov/ordering.htm 